\title{
Democratic public good provision
}

\author{
John Hassler ${ }^{\mathrm{a}, \mathrm{b}}$, Kjetil Storesletten ${ }^{\mathrm{b}, \mathrm{c}, *}$, Fabrizio Zilibotti $^{\mathrm{a}, \mathrm{b}}$ \\ ${ }^{a}$ Institute for International Economic Studies, Stockholm University, S-10691 Stockholm, Sweden \\ ${ }^{\mathrm{b}}$ CEPR, London, UK \\ ${ }^{\mathrm{c}}$ Department of Economics, University of Oslo, Box 1095 Blindern, N-0317 Oslo, Norway
}

Received 20 February 2003; final version received 27 July 2005

Available online 20 February 2006

\begin{abstract}
This paper analyzes an overlapping generation model of redistribution and public good provision under repeated voting. Expenditures are financed through age-dependent taxation that distorts human capital investment. Taxes redistribute income both across skill groups and across generations. We focus on politicoeconomic Markov equilibria and contrast these with the Ramsey allocation under commitment. The model features indeterminate equilibria, with a key role of forward-looking strategic voting. Due to the lack of commitment to future policies, the tax burden may be on the wrong side of the dynamic Laffer curve. Moreover, restrictions on government policies can in some cases be welfare improving.
\end{abstract}

(C) 2005 Elsevier Inc. All rights reserved.

JEL classification: D72; D78; E62; H21; H41; H53

Keywords: Markov equilibrium; Political economy; Redistribution; Repeated voting; Multiple equilibria; Public good; Ramsey taxation

\section{Introduction}

This paper proposes a dynamic theory of public good provision when taxation and the allocation of government expenditure are determined in repeated elections. We consider an environment where government expenditure is financed by income taxation and the tax rates can vary across age groups. Since voters are heterogenous in human capital and earnings but benefit equally from public good provision, they have conflicting interests on government expenditure. The theory predicts rich dynamic interactions between economics and politics: distortionary taxation, which

\footnotetext{
* Corresponding author. Department of Economics, University of Oslo, Box 1095 Blindern, N-0317 Oslo, Norway. Fax: +4722855035 .

E-mail addresses: john@ hassler.se (J. Hassler), kjstore@econ.uio.no (K. Storesletten), fabrizio.zilibotti@iies.su.se (F. Zilibotti).
} 
is voted upon period-by-period, affects private human capital investments. Thus, the current political choice affects future human capital and income distribution which, in turn, determines future voting outcomes. The dynamic link between present and future political choice opens a scope for strategic voting.

We characterize the set of stationary Markov political equilibria and show that equilibrium is indeterminate. There exists one "sincere" equilibrium with high taxes where the poor are politically decisive, and a range of "strategic" equilibria with lower taxes where the rich are politically decisive. In the latter, the median voter strategically opts for low taxation on the young so as to generate a future political majority against high taxation reducing current distortions.

There are large and well-known cross-country differences in the size and composition of government expenditures. For example, in Scandinavian countries, the average size of government measured by tax revenue is more than half the size of GDP, while it is below one-quarter of GDP in the United States and Switzerland. Our theory shows that such differences are not necessarily due to variation in exogeneous factors-we show that otherwise identical economies may opt for quite different levels of taxation and public good provision. The multiplicity in our model is driven by strategic voting and forward-looking expectations, and does neither rely on differences in initial conditions nor on imperfect learning about the distortionary effects of taxation (unlike $[3,15])$. Moreover, while much of the existing politico-economic literature has emphasized factors leading to excess taxation, some of the (strategic) equilibria in our paper feature too low taxation and underprovision of public goods.

In addition, the theory provides novel insights about the politico-economic determination of the composition of public expenditure. Governments can spend their revenue on public goods benefitting all agents (such as judicial system, health, parks or infrastructure) or on transfer programs targeted to the poor (such as welfare and unemployment). The multiplicity of equilibria carries over to an environment where both the composition and the amount of government expenditure are endogenous. However, strategic equilibria, where the median voter is a rich old agent, reveal a new feature: when the marginal utility of public goods is low, the composition of government expenditure is inefficient. Since the tax revenue must be spent either on a public good or on programs targeted to the poor, the old rich will, when they are decisive, allocate all expenditure to public good programs even if these have low social value ("white elephants"). In spite of its inefficiency, this political outcome is sustained over time, i.e., a majority of old rich endogenously regenerates itself and continue to demand "white elephants".

These findings relate to a literature comparing the composition of government spending in different political systems. In [12], office-competing political candidates make promises on two different types of activities: a pure public good and transfers targeted to specific voters. To win swing-voters, political parties promise "pork-barrel" spending, and in equilibrium, the provision of the shared public good is inefficiently low. The paper analyzes how the electoral system shapes this bias against the shared public good (see also [13], for empirical evidence). The reason why our model, in contrast to theirs, can predict over-provision of the public good, is that we impose more restrictions on who can be targeted; while the decisive voters in our model can target taxes to other age-groups, the rich cannot target net transfers to themselves. These stylized assumptions, which we find empirically plausible, allow a rich analysis of dynamic voting motives (which are absent in [12]). ${ }^{1}$ Robinson and Torvik [16] focus on over-provision of low-quality public goods, more in line with our paper although emphasizing a different channel. They analyze projects stretching

\footnotetext{
${ }^{1}$ We believe it would be quite interesting to extend our framework to allow more targeted taxes and transfers, along the lines of Lizzeri and Persico [12], and investigate dynamic aspects of electoral rules.
} 
over more than one election cycle, assuming that future refinancing is critical for completion of the project. Good projects are refinanced by all candidates, while only some candidates can credibly promise to refinance bad projects. Thus, an incumbent may, for strategic reasons, launch "white elephants" to secure future support from the voters benefitting from the project.

The focal point of this paper is the dynamics of the choice of public policy in a repeated, dynamic setting. A similar model was analyzed in Hassler et al. [9]. In that paper, we show that an inefficient transfer system, i.e., a system that all agents would, when they are young, like to remove, can survive over time. This is because the policy distorts incentives in a way that regenerates its political constituency over time. The current paper differs from the previous one in several important respects. First, in that paper, we considered redistribution via monetary transfers only. In the data, a large share of government expenditures is allocated to provision of goods with important (albeit varying) public good components such as education, defence, infrastructure, the judicial system, etc. As we shall see, the public good character of such expenditures is key for our results. Second, in the earlier paper, the fiscal tools for inter-generational redistribution were limited; policies were restricted to be age-independent. In reality, taxes and benefits have important age-dependent elements. Allowing for age-dependent redistribution has major implications for the dynamics and, as a consequence, the analytical characterization in the present work is simpler, thereby making this model of independent methodological interest.

Other forebears to our analysis include [1,4,14]. Besley and Coate [4] analyze public good provision in a citizen-candidate model. They identify several reasons why the political outcome is Pareto inefficient. Some of these sources of "political failure" are present here as well, and include the inability to commit to moderate future taxation of the old (which may drive inefficiencies in our sincere equilibrium) and the adjustment in policy to induce or avoid a change in the identity of the future median voter (which may drive inefficiencies in our strategic equilibria). Recent papers in the growing wave of dynamic (Markov) politico-economic literature include $[2,5-8,17,18] .^{2}$

The paper is organized as follows. Section 2 presents the model and Section 3 characterizes the Ramsey allocations. Section 4 analyzes political equilibria with general spending and public goods. Section 5 introduces targeted spending and Section 6 concludes. Proofs are provided in the Appendix.

\section{The model}

The model economy consists of a continuum of two-period lived agents. Each generation has a unit mass. Agents are, at birth, of two types: high-ability and low-ability, in proportion $\mu$ and $1-\mu$, respectively. High-ability agents can affect their prospects in life by an initial (educational) investment. In particular, they either become rich or poor, and by undertaking a costly investment, they can increase the probability $e$ of becoming rich. The cost of investment is quadratic and equal to $e^{2}$. Rich agents earn a high wage, normalized to unity, in both periods, whereas poor agents earn a low wage, normalized to zero. Low-ability agents make no investment choice; irrespective of their private actions, they are deemed to poverty.

The government provides transfers (s) and a public good (g), financed by income taxes levied on the rich. In the benchmark case, we focus on lump-sum general transfers paid to all agents. Targeted transfers are discussed in Section 5. The tax rates are allowed to be age-dependent,

\footnotetext{
${ }^{2}$ Among these papers, [2,18] are those most closely related to ours. In [2], successive governments have different preferences over public goods and use debt and investment policies to influence future public good provision. In [18], the model of this paper is developed and extended to introduce persistent aggregate "ideological" shocks to voters' preferences.
} 
$\tau^{\mathrm{O}}$ for the old and $\tau^{\mathrm{Y}}$ for the young, but restricted to lie between 0 and $100 \%$. Since only the rich pay taxes, public goods and transfers are redistributive. The tax rates are determined before the young agents decide on their investment and the government budget balances in every period.

The expected utility of agents alive at time $t$ is given as follows:

$$
\begin{aligned}
V_{t}^{o s}= & V^{o s}\left(g_{t}, s_{t}, \tau_{t}^{\mathrm{O}}\right)=1-\tau_{t}^{\mathrm{O}}+a g_{t}+s_{t}, \\
V_{t}^{o u}= & V^{o u}\left(g_{t}, s_{t}\right)=a g_{t}+s_{t}, \\
V_{t}^{o l}= & V^{o l}\left(g_{t}, s_{t}\right)=a g_{t}+s_{t}, \\
V_{t}^{y}= & V^{y}\left(e_{t}, g_{t}, g_{t+1}, s_{t}, s_{t+1}, \tau_{t}^{\mathrm{Y}}, \tau_{t+1}^{\mathrm{O}}\right)=e_{t}\left(1+\beta-\tau_{t}^{\mathrm{Y}}-\beta \tau_{t+1}^{\mathrm{O}}\right) \\
& +a\left(g_{t}+\beta g_{t+1}\right)+s_{t}+\beta s_{t+1}-e_{t}^{2}, \\
V_{t}^{y l}= & V^{y l}\left(g_{t}, g_{t+1}, s_{t}, s_{t+1}\right)=a\left(g_{t}+\beta g_{t+1}\right)+s_{t}+\beta s_{t+1},
\end{aligned}
$$

where $V_{t}^{o s}, V_{t}^{o u}$ and $V_{t}^{o l}$ denote the utility of old rich, old poor and old low-ability types in period $t$, and $V_{t}^{y}$ and $V_{t}^{y l}$ denote expected utility of young high-ability and young low-ability agents born in period $t$. Note that $V^{y}$ is computed prior to individual success or failure. $\beta \in[0,1]$ is the discount factor and $a$ is the marginal utility of the public good. The assumption that this marginal utility is constant is for tractability.

Given these preferences, the optimal investment of young high-ability agents is

$$
e^{*}\left(\tau_{t}^{\mathrm{Y}}, \tau_{t+1}^{\mathrm{O}}\right)=\left(1+\beta-\tau_{t}^{\mathrm{Y}}-\beta \tau_{t+1}^{\mathrm{O}}\right) / 2
$$

Since high-ability agents are identical ex ante, agents of the same cohort choose the same investment, implying that the proportion of old poor in period $t+1$ is given by

$$
u_{t+1}=1-e^{*}\left(\tau_{t}^{\mathrm{Y}}, \tau_{t+1}^{\mathrm{O}}\right)=\left(1-\beta+\tau_{t}^{\mathrm{Y}}+\beta \tau_{t+1}^{\mathrm{O}}\right) / 2 \text {. }
$$

Thus, the proportion of old poor at $t+1$ depends on the income tax rate levied on the rich young at $t+1$ and on the discounted tax rate levied on the rich old at $t+1$. The cost of the public good is normalized to one, implying that the balanced government budget can be expressed as

$$
g_{t}+2 s_{t}=\mu\left(1-u_{t}\right) \tau_{t}^{\mathrm{O}}+\mu e^{*}\left(\tau_{t}^{\mathrm{Y}}, \tau_{t+1}^{\mathrm{O}}\right) \tau_{t}^{\mathrm{Y}} .
$$

We conclude this section by defining the set of feasible allocations in this economy:

Definition 1. A feasible allocation is a sequence of public good provisions, transfers, taxes and investments $\left\{g_{t}, s_{t}, \tau_{t}^{\mathrm{Y}}, \tau_{t}^{\mathrm{O}}, e_{t}\right\}_{t=0}^{\infty}$ that satisfies the implementability constraint, (2), the balanced budget constraint, (3), $g_{t} \geqslant 0, s_{t} \geqslant 0$ and $\tau_{t}^{\mathrm{O}}, \tau_{t}^{\mathrm{Y}} \in[0,1] \forall t$.

\section{Efficient allocations}

In this section, we characterize the Ramsey allocation in the benchmark case where the tax revenue can be spent on public goods or general transfers. A Ramsey allocation is defined as a feasible plan chosen by a benevolent social planner who can commit to a policy sequence at time 
zero. The allocation solves the following program:

$$
\begin{aligned}
& \max _{\left\{g_{t}, s_{t}, \tau_{t}^{\mathrm{Y}}, \tau_{t}^{\mathrm{O}}\right\}_{t=0}^{\infty}}\left\{\beta \mu\left(1-u_{0}\right) V^{o s}\left(g_{0}, s_{0}, \tau_{t}^{\mathrm{O}}\right)+\beta\left(\mu u_{0}+(1-\mu) H\right) V^{\text {ou }}\left(g_{0}, s_{0}, \tau_{t}^{\mathrm{O}}\right)\right. \\
& +\sum_{t=0}^{\infty} \lambda^{t}\left(V^{y}\left(e_{t}, g_{t}, g_{t+1}, s_{t}, s_{t+1}, \tau_{t}^{\mathrm{Y}}, \tau_{t+1}^{\mathrm{O}}\right)\right. \\
& \left.\left.+(1-\mu) H V^{y l}\left(g_{t}, g_{t+1}, s_{t}, s_{t+1}\right)\right)\right\},
\end{aligned}
$$

Note that the planner discounts future generations' utilities with a "discount factor" $\lambda \in[0,1)$. Furthermore, the utility of the initial generation of old agents is weighted by $\beta$. This implies that a planner who sets $\lambda=\beta$ attaches the same weight to the felicity of the young born at $t$ and that of the old born at $t-1$. If $\lambda<\beta$ (or, alternatively, $\lambda>\beta$ ), the planner attaches a smaller (larger) weight to the former than to the latter; or, in other terms, $\lambda<\beta$ (or, alternatively, $\lambda>\beta$ ) reflects a bias in the planner's preferences in favor of old (young) agents. We also allow the planner to have a bias in favor of redistribution towards low-ability agents, parameterized by the constant $H \geqslant 1$. However, she has no such bias towards high-ability low-income agents. ${ }^{3}$

We start our analysis by establishing that public good provision Pareto-dominates (are Paretodominated by) general transfers if the marginal utility agents derive from the public good exceeds (falls short of) one half, i.e. if $a \lessgtr \frac{1}{2}$.

Lemma 1. If $a>\frac{1}{2}$ (respectively, $a<\frac{1}{2}$ ) thenfor any feasible allocation $\left\{g_{t}, s_{t}, \tau_{t}^{\mathrm{Y}}, \tau_{t}^{\mathrm{O}}\right\}_{t=0}^{\infty}$ such that $s_{t}>0$ (respectively $g_{t}>0$ ) for some $t \geqslant 0$, there exists anotherfeasible allocation $\left\{\hat{g}_{t}, \hat{s}_{t}, \tau_{t}^{\mathrm{Y}}\right.$, $\left.\tau_{t}^{\mathrm{O}}\right\}_{t=0}^{\infty}\left(\left\{\tilde{g}_{t}, \tilde{s}_{t}, \tau_{t}^{\mathrm{Y}}, \tau_{t}^{\mathrm{O}}\right\}_{t=0}^{\infty}\right)$ that renders no agents worse off and some agents strictly better off, where, for all $t \geqslant 0$ :

$$
\hat{g}_{t}=g_{t}+2 s_{t} \text { and } \hat{s}_{t}=0\left(\tilde{s}_{t}=s_{t}+g_{t} / 2 \quad \text { and } \quad \tilde{g}_{t}=0\right) .
$$

If $a=\frac{1}{2}$ then all agents are indifferent with respect to the composition of public expenditure.

The proof is by direct inspection and details are omitted. An immediate implication of Lemma 1 is that a planner with access to direct transfers, as well as public good provision, will spend the entire budget on public goods if $a>\frac{1}{2}$, and on direct transfers if $a<\frac{1}{2}$. Using these implications, and substituting in the government budget constraint, (3), the planner's objective function, (4), can then be rewritten as follows:

$$
\begin{aligned}
& \tilde{L}\left(u_{0}\right)=\max _{\left\{\tau_{t}^{\mathrm{Y}} \in[0,1], \tau_{t}^{\mathrm{O}} \in[0,1]\right\}_{t=0}^{\infty}}\left\{\beta \mu\left(1-u_{0}\right)\left(1-\tau_{0}^{\mathrm{O}}\right)+(\beta+\lambda) A \mu\left(1-u_{0}\right) \tau_{0}^{\mathrm{O}}\right. \\
& +\sum_{t=0}^{\infty} \lambda^{t}\left(\lambda \mu\left(\left(1-\tau_{t}^{\mathrm{Y}}+\beta\left(1-\tau_{t+1}^{\mathrm{O}}\right)\right) e^{*}\left(\tau_{t}^{\mathrm{Y}}, \tau_{t+1}^{\mathrm{O}}\right)-\left(e^{*}\left(\tau_{t}^{\mathrm{Y}}, \tau_{t+1}^{\mathrm{O}}\right)\right)^{2}\right)\right. \\
& \left.\left.+(\beta+\lambda) A \mu \tau_{t}^{\mathrm{Y}} e^{*}\left(\tau_{t}^{\mathrm{Y}}, \tau_{t+1}^{\mathrm{O}}\right)+\lambda(\beta+\lambda) A \mu \tau_{t+1}^{\mathrm{O}} e^{*}\left(\tau_{t}^{\mathrm{Y}}, \tau_{t+1}^{\mathrm{O}}\right)\right)\right\},
\end{aligned}
$$

where $A \equiv(\mu+(1-\mu) H) \cdot \max \left\{a, \frac{1}{2}\right\} \geqslant \frac{1}{2}$ is the planner's marginal value of expenditures. Moreover, the function $e^{*}$ is given by $(2)$, and the terms $\mu \tau_{t}^{\mathrm{Y}} e^{*}\left(\tau_{t}^{\mathrm{Y}}, \tau_{t+1}^{\mathrm{O}}\right)$ and $\mu \tau_{t}^{\mathrm{O}} e^{*}\left(\tau_{t}^{\mathrm{Y}}, \tau_{t+1}^{\mathrm{O}}\right)$

\footnotetext{
${ }^{3}$ This is equivalent to assuming that the planner is utilitarian, but low-ability agents have a higher marginal utility of consumption (of both private and public goods) due to a lower level of other endowments.
} 
denote the tax revenue financed by the young and the old at $t$, respectively. Note that, if $H=1$, the objective function is proportional to the parameter $\mu$, which implies that the Ramsey taxes will be invariant to this parameter. The reason is that tax revenue is proportional to $\mu$, since only the rich are taxed (see Eq. (3)).

While dynamic in nature, the Ramsey problem in (5) admits a simple static representation. To see this, note that the program can be rewritten as follows:

$$
\tilde{L}\left(u_{0}\right)=\max _{\left\{\tau_{0}^{\mathrm{O}} \in[0,1]\right\}}\left\{\beta \mu\left(1-u_{0}\right)\left(1-\tau_{0}^{\mathrm{O}}\right)+(\beta+\lambda) A \mu\left(1-u_{0}\right) \tau_{0}^{\mathrm{O}}+\frac{L}{1-\lambda}\right\},
$$

where

$$
\begin{aligned}
& L=\max _{\left\{\tau^{\mathrm{Y}} \in[0,1], \tau^{\mathrm{O}} \in[0,1]\right\}}\left\{\lambda \mu\left(\left(1-\tau^{\mathrm{Y}}+\beta\left(1-\tau^{\mathrm{O}}\right)\right) e^{*}\left(\tau^{\mathrm{Y}}, \tau^{\mathrm{O}}\right)-\left(e^{*}\left(\tau^{\mathrm{Y}}, \tau^{\mathrm{O}}\right)\right)^{2}\right)\right. \\
& \left.+(\beta+\lambda) A \mu \tau^{\mathrm{Y}} e^{*}\left(\tau^{\mathrm{Y}}, \tau^{\mathrm{O}}\right)+\lambda(\beta+\lambda) A \mu \tau^{\mathrm{O}} e^{*}\left(\tau^{\mathrm{Y}}, \tau^{\mathrm{O}}\right)\right\} .
\end{aligned}
$$

In plain words, after the initial choice of $\tau_{0}^{\mathrm{O}}$, the problem reduces to a sequence of identical static optimization problems over $\tau^{\mathrm{Y}}$ and $\tau^{\mathrm{O}}$, without any state variable. ${ }^{4}$

The solution to program (6) is straightforward. Since $\tau_{0}^{\mathrm{O}}$ has no distortionary effects and there is no interaction with future variables, the planner sets $\tau_{0}^{\mathrm{O}}=1$ if $A>\beta /(\beta+\lambda)$ and $\tau_{0}^{\mathrm{O}}=0$ otherwise. Next, consider the continuation program, (7). As mentioned above, $\lambda$ parameterizes the inter-generational bias of the planner. If $\lambda \rightarrow 1$, she maximizes $\mu V^{y}+(1-\mu) H V^{y l}$ — the average expected utility of young agents, weighted by the pro-low ability bias. This is our model's counterpart to the "golden rule". If instead $\lambda \rightarrow 0$, the planner ignores future generations and maximizes the average ex post utility of old agents. That is, she maximizes $e^{*}\left(\tau^{\mathrm{Y}}, \tau^{\mathrm{O}}\right) \tau^{\mathrm{Y}}-$ the tax revenue the old can extract from the young. The knife-edge case $\lambda=\beta$ corresponds to a perfectly utilitarian planner with the same regard for the ex post utility of old agents as for the ex ante utility of future generations.

The next proposition characterizes the Ramsey allocation.

Proposition 1. The allocation solving the Ramsey problem (6)-(7) has

$$
\tau_{0}^{\mathrm{O}}= \begin{cases}1 & \text { if } A>\frac{\beta}{\beta+\lambda}, \\ 0 & \text { else }\end{cases}
$$

and a constant sequence of taxes, $\tau^{\mathrm{Y}}$ and $\tau^{\mathrm{O}}$ given by the following:

1. If $\lambda<\beta$, then,

$$
\tau^{\mathrm{Y}}=(1+\beta) \frac{A-\lambda /(\beta+\lambda)}{2 A-\lambda /(\beta+\lambda)}, \quad \tau^{\mathrm{O}}=0 .
$$

2. If $\lambda>\beta$, then

$$
\tau^{\mathrm{Y}}=\max \left[0, \frac{A(1-\lambda)-\lambda /(\beta+\lambda)}{2 A-\lambda /(\beta+\lambda)}\right], \quad \tau^{\mathrm{O}}=\min \left[\frac{1+\beta}{\beta} \frac{A-\beta /(\beta+\lambda)}{2 A-\beta /(\beta+\lambda)}, 1\right] .
$$

\footnotetext{
${ }^{4}$ Note that this formulation abuses the notation slightly, since $\tau^{\mathrm{Y}}$ and $\tau^{\mathrm{O}}$ in Eq. (7) refer to current tax on the young and next period's tax on the old (i.e., for any $t \geqslant 0$, we have $\tau_{t}^{\mathrm{Y}}=\tau^{\mathrm{Y}}$ and $\tau_{t+1}^{\mathrm{O}}=\tau^{\mathrm{O}}$ ).
} 

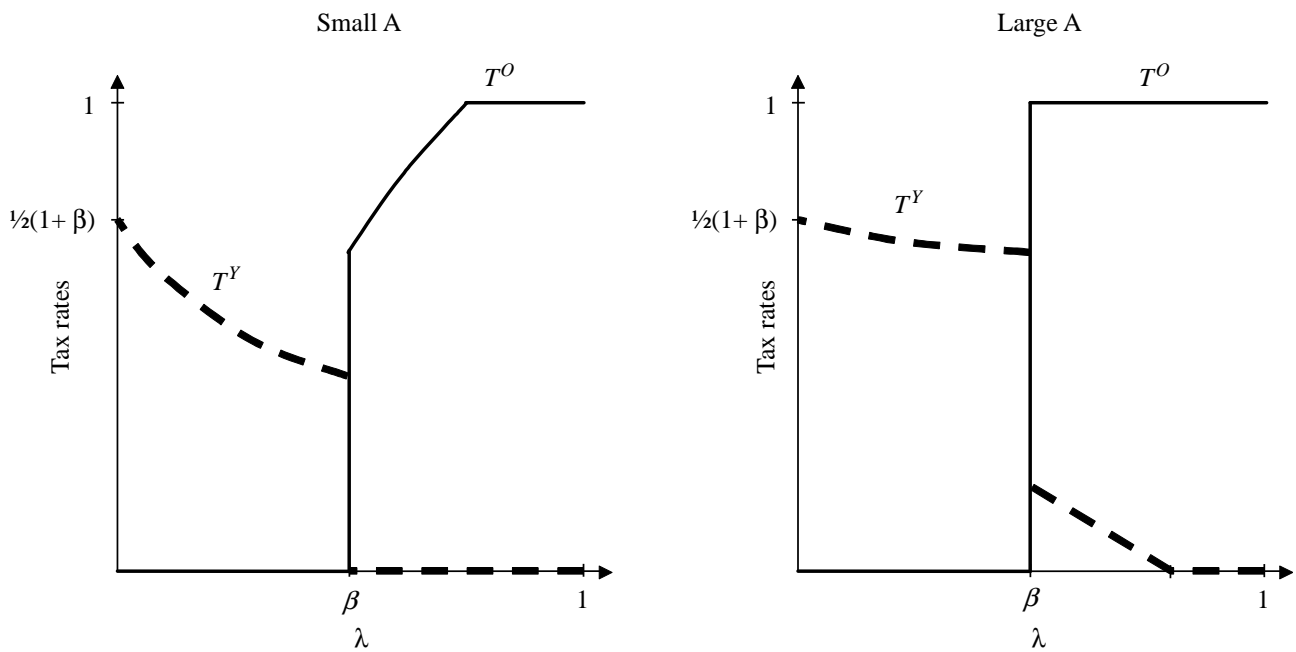

Fig. 1. The figures represents tax rates, $T^{\mathrm{Y}}$ and $T^{\mathrm{O}}$, as a function of the planner's discount factor $\lambda$ in the Ramsey allocations of Proposition 1. The left-hand (right-hand) panel shows the optimal tax rates when the marginal value of expenditures, $A$, is relatively small (large). In the figures, the private discount factor and the fraction of high-ability agents are held constant at $\beta=\frac{1}{2}$, and $\mu=1$.

3. If $\lambda=\beta$, then

$$
\tau^{\mathrm{Y}}+\beta \tau^{\mathrm{O}}=\frac{(2 A-1)(1+\beta)}{4 A-1} .
$$

Fig. 1 shows the tax rates in the Ramsey allocations as a function of $\lambda$ for two different values of $A$. For $\lambda<\beta$, i.e. part 1 of the proposition, the tax burden falls on the young (in both panels). For $\lambda=\beta$ (part 3 of the proposition), the distribution of the tax burden is indeterminate. When $\lambda>\beta$ (part 2 of the proposition), most of the tax burden falls on the old. For a range of small $A$ 's (left-hand panel), the non-negativity constraint on $\tau^{\mathrm{Y}}$ binds for all $\lambda>\beta$, and the planner sets $\tau^{\mathrm{Y}}=0$. Instead, the constraint that $\tau^{\mathrm{O}} \leqslant 1$ is binding for large $\lambda$ 's. In the complementary range (large $A$, right-hand panel), the constraint that $\tau^{\mathrm{O}} \leqslant 1$ is always binding, whereas the non-negativity constraint on $\tau^{\mathrm{Y}}$ only binds for sufficiently large $\lambda$ 's. In all cases, the tax rates on both the young and the old, as well as the present discounted value of the tax revenue, are non-decreasing in $A$. Intuitively, a higher value of the public good induces the planner to increase taxation.

To gain some intuition for Proposition 1, consider the knife-edge utilitarian case, $\beta=\lambda$. In this case, the planner chooses $x \equiv \tau^{\mathrm{Y}}+\beta \tau^{\mathrm{O}}$, i.e. the present value of taxation faced by each young agent, so as to maximize

$$
\bar{L}(x)=\left((1+\beta-x) e^{*}(x)-\left(e^{*}(x)\right)^{2}\right)+2 A x e^{*}(x),
$$

where the first term captures the cost of taxation while the second term captures its benefits. Using the envelope theorem, the optimal solution simplifies to $e^{*}(x)=A(1+\beta-2 x)$, equalizing the marginal cost of taxation with the marginal benefit of expenditures (on public goods or transfers). In this knife-edge case, the planner is indifferent as to how to split the tax burden between the young and the old. In contrast, the present value of taxation is determinate. 
When $\beta \neq \lambda$, however, the split between $\tau^{\mathrm{Y}}$ and $\tau^{\mathrm{O}}$ ceases to be indeterminate, since the planner cares about inter-generational distributional effects. In particular, shifting the tax burden towards the young (old) increases (decreases) the ex post utility of the old agents at the expense (in favor of) future generations. For instance, as $\lambda \rightarrow 0$, the planner wishes to maximize the tax revenue collected from the young, i.e., she maximizes $\tau^{\mathrm{Y}} e^{*}\left(\tau^{\mathrm{Y}}, \tau^{\mathrm{O}}\right)$ (see Eq. (7)). This is achieved by setting $\tau^{\mathrm{O}}=0$ and choosing $\tau^{\mathrm{Y}}$ so as to attain the top of the Laffer curve. ${ }^{5}$ Conversely, as $\lambda \rightarrow 1$, the planner maximizes the ex ante utility of the young, and prefers to tax the old. The reason is that individual agents discount the effects of future taxation when deciding on their investment, thereby implying that taxes on the old are less distortionary.

An interesting question is what allocation would be chosen by a planner who cares only about the low-ability agents and does not discount the utility of future generations (a "Rawlsian" planner). This is naturally parameterized by letting $H \rightarrow \infty$ and $\lambda \rightarrow 1$. A planner with such preferences sets taxation so as to maximize the steady-state expenditures on public goods (when $a \geqslant \frac{1}{2}$ ) or transfers (when $a<\frac{1}{2}$ ).

Corollary 1. The Rawlsian planner allocation has the following constant sequence of taxes: $\tau_{t}^{\mathrm{Y}}=0$ and $\tau_{t}^{\mathrm{O}}=1$ for all $t \geqslant 0$.

The proof follows immediately from letting $A \rightarrow \infty$ and $\lambda \rightarrow 1$ in part 2 of Proposition 1 .

\section{Political equilibrium}

\subsection{Equilibrium definition}

In this section, we characterize the equilibrium tax sequence when policies are set through repeated voting. Agents vote on taxation period-by-period and decide how the tax revenue should be spent. Elections are held at the end of each period and the elected politician sets tax rates for the following period. The old have no interests at stake and are assumed to abstain. Moreover, the young know their wage realization. This is observationally equivalent to assuming that agents vote over current taxes at the beginning of each period, but that only the old vote. For expositional ease, we focus on the latter interpretation in the presentation. ${ }^{6}$

Voters choose both the tax rates and the allocation of spending between public goods and general transfers. It is straightforward to see that, for any level of tax revenue collected, all agents will agree on how to spend it. In particular, if $a \geqslant \frac{1}{2}$, agents choose public good provision, while if $a<\frac{1}{2}$, they choose general transfers. ${ }^{7}$

\footnotetext{
${ }^{5}$ Another way of illustrating the result in this limit case is the following. When $\lambda=0$, the planner only cares about the utility of the old at time zero. Thus, she sets $\tau_{1}^{\mathrm{O}}=0$, since future taxation is of no value for the current old, but distorts the incentives of the young.

${ }^{6}$ Following [9], these timing assumptions emphasize the predominance of ex post interests in determining political outcomes. If agents instead voted at the beginning of the period in our two-period framework, $50 \%$ of the voters would not yet have decided on their human capital investment. In any generalization with more than two periods, however, it would be natural to assume that a majority of voters had already undertaken such investment. Therefore, our timing assumption is a natural way of avoiding this artifact of the two-period model. In an earlier version of this paper, we also analyzed the case when all agents vote over current taxation at the beginning of each period [10].

${ }^{7}$ Formally, the composition of expenditure should also be part of the definition of Markov equilibrium below. However, given the simplicity of this choice, we omit this formalism.
} 
We focus on stationary Markov-perfect equilibria, where the state of the economy is summarized by the proportion of current poor old agents $\left(u_{t}\right)$. A convenient feature of the model is that tax revenue in period $t, \mu\left(1-u_{t}\right) \tau_{t}^{\mathrm{O}}+\mu e^{*}\left(\tau_{t}^{\mathrm{Y}}, \tau_{t+1}^{\mathrm{O}}\right) \tau_{t}^{\mathrm{Y}}$, is additively separable in two components, representing the tax revenue financed by the old (to be denoted by $W\left(u_{t}, \tau_{t}^{\mathrm{O}}\right)$ ) and that financed by the young (to be denoted by $Z\left(\tau_{t}^{\mathrm{Y}}, \tau_{t+1}^{\mathrm{O}}\right)$ ), respectively. Hence, the utilities of all voters at $t$ can be separated into a term depending on $\tau_{t}^{\mathrm{O}}$ and $u_{t}$ (but no future variables) and a term depending on $\tau_{t}^{\mathrm{Y}}$ and $\tau_{t+1}^{\mathrm{O}}$ (but no predetermined variables). An implication of this separability is that the state variable $u_{t}$ only affects the political choice of $\tau_{t}^{\mathrm{O}}$. Preferences over $\tau_{t}^{\mathrm{Y}}$ and $\tau_{t+1}^{\mathrm{O}}$ are instead entirely forward looking and independent of the state variable.

Formally, the utility of the old rich and poor, respectively, can be rewritten as

$$
\begin{aligned}
& V_{t}^{o s}=1-\tau_{t}^{\mathrm{O}}+\hat{a}\left(W\left(u_{t}, \tau_{t}^{\mathrm{O}}\right)+Z\left(\tau_{t}^{\mathrm{Y}}, \tau_{t+1}^{\mathrm{O}}\right)\right), \\
& V_{t}^{\text {ou }}=V_{t}^{o l}=\hat{a}\left(W\left(u_{t}, \tau_{t}^{\mathrm{O}}\right)+Z\left(\tau_{t}^{\mathrm{Y}}, \tau_{t+1}^{\mathrm{O}}\right)\right),
\end{aligned}
$$

where

$$
\begin{aligned}
W\left(u_{t}, \tau_{t}^{\mathrm{O}}\right) & =\mu\left(1-u_{t}\right) \tau_{t}^{\mathrm{O}} \\
Z\left(\tau_{t}^{\mathrm{Y}}, \tau_{t+1}^{\mathrm{O}}\right) & =\mu e^{*}\left(\tau_{t}^{\mathrm{Y}}, \tau_{t+1}^{\mathrm{O}}\right) \tau_{t}^{\mathrm{Y}},
\end{aligned}
$$

and where the parameter $\hat{a} \equiv \max \left\{a, \frac{1}{2}\right\}$ reflects the fact that if $a<\frac{1}{2}$, the revenue is spent on transfers.

We focus the discussion on the interesting case where $a \leqslant 1 / \mu$. This implies that whatever the level of $u_{t}$, the old rich would never tax themselves to finance public good or transfers. Thus, there is an intra-generational political conflict among the old voters: the rich prefer zero taxes on the old, while the poor prefer $100 \%$ taxation on the old. However, irrespective of $a$, the old agents' preferences over $\tau_{t}^{\mathrm{Y}}$ are perfectly aligned: they wish to maximize $Z\left(\tau_{t}^{\mathrm{Y}}, \tau_{t+1}^{\mathrm{O}}\right)$, thereby attaining the top of the Laffer curve.

We can now provide the equilibrium definition. The superscript dec will denote the identity of the "decisive" voter. The identity of such a voter (old rich or old poor) depends on the state of the economy. We assume the political decisions are to be made through majority voting where voters elect an office-seeking politician proposing income tax rates on the old and the young. The politician will simply set policies to maximize the utility of the larger group.

Definition 2. A (stationary Markov perfect) political equilibrium is defined as a triplet of functions $\left\langle T^{\mathrm{O}}, T^{\mathrm{Y}}, U\right\rangle$, where $T^{\mathrm{O}}:[0,1] \rightarrow[0,1]$ and $T^{\mathrm{Y}}$ are two public policy rules, $\tau_{t}^{\mathrm{O}}=T^{\mathrm{O}}\left(u_{t}\right)$ and $\tau_{t}^{\mathrm{Y}}=T^{\mathrm{Y}}$, and $U:[0,1] \rightarrow[0,1]$ is a private decision rule, $u_{t+1}=U\left(\tau_{t}^{\mathrm{Y}}\right)$, such that given $u_{0}$, the following functional equations hold:

1. $T^{\mathrm{O}}\left(u_{t}\right)=\arg \max _{\tau_{t}^{\mathrm{O}} \in[0,1]} W^{\mathrm{dec}}\left(\tau_{t}^{\mathrm{O}}, u_{t}\right)$, where

$$
W^{\mathrm{dec}}\left(u_{t}, \tau_{t}^{\mathrm{O}}\right)= \begin{cases}1-\tau_{t}^{\mathrm{O}}+\hat{a} W\left(u_{t}, \tau_{t}^{\mathrm{O}}\right) & \text { if } u_{t} \leqslant 1-1 /(2 \mu), \\ \hat{a} W\left(u_{t}, \tau_{t}^{\mathrm{O}}\right) & \text { if } u_{t}>1-1 /(2 \mu)\end{cases}
$$

2. $U\left(\tau_{t}^{\mathrm{Y}}\right)=1-e^{*}\left(\tau_{t}^{\mathrm{Y}}, \tau_{t+1}^{\mathrm{O}}\right)$, with $\tau_{t+1}^{\mathrm{O}}=T^{\mathrm{O}}\left(U\left(\tau_{t}^{\mathrm{Y}}\right)\right)$.

3. $T^{\mathrm{Y}}=\arg \max _{\tau_{t}^{\mathrm{Y}} \in[0,1]} \hat{a} Z\left(\tau_{t}^{\mathrm{Y}}, \tau_{t+1}^{\mathrm{O}}\right)$ subject to $\tau_{t+1}^{\mathrm{O}}=T^{\mathrm{O}}\left(U\left(\tau_{t}^{\mathrm{Y}}\right)\right)$. 
The first equilibrium condition requires that $\tau_{t}^{\mathrm{O}}$ maximizes the utility of the decisive old voter who is either the old rich (if $u_{t}<1-1 /(2 \mu)$ ) or the old poor (if $u_{t}>1-1 /(2 \mu)$ ). We assume that in case of an equal number of rich and poor old voters (i.e. $u_{t}=1-1 /(2 \mu)$ ) the rich decide. As discussed above, the optimal choice of $\tau_{t}^{\mathrm{O}}$ is independent of $\tau_{t}^{\mathrm{Y}}$ and any future variables. The second equilibrium condition implies that all young individuals choose their investment optimally, given $\tau_{t}^{\mathrm{Y}}$ and $\tau_{t+1}^{\mathrm{O}}$, and that agents hold rational expectations about future taxes and distributions of types. The third equilibrium condition requires that even $\tau_{t}^{\mathrm{Y}}$ maximizes the objective function of the decisive voter. Rational voters understand that their choice over current redistribution affects future redistribution via the private decision rule and public policy rules. In equilibrium, $\tau_{t}^{\mathrm{Y}}=T^{\mathrm{Y}}$ is constant (for a given investment rule $U$ ), since the function $Z$ (.) does not depend on the state variable.

\subsection{Characterizing political equilibria}

The three equilibrium conditions can be solved recursively. First, condition 1 defines a oneto-one mapping from the state variable $u_{t}$ to the equilibrium choice of taxation of the old, i.e. $\tau_{t}^{\mathrm{O}}=T^{\mathrm{O}}\left(u_{t}\right)$. Second, condition 2 defines a functional equation whose solution is the optimal investment schedule as a function of the current taxation of the young. This solution is, as we shall see, indeterminate. Third, given $T^{\mathrm{O}}$ (.) and $U$ (.), condition 3 defines the choice of the current taxation today. The strategic voting motive arises from agents recognizing that $\tau_{t}^{\mathrm{Y}}$ affects $\tau_{t+1}^{\mathrm{O}}$ via equilibrium policies $T^{\mathrm{O}}$ (.) and $U($.).

Given (11), if $a \leqslant 1 / \mu$, the equilibrium mapping $T^{\mathrm{O}}\left(u_{t}\right)$ (see equilibrium condition 1 ) is as follows:

$$
T^{\mathrm{O}}\left(u_{t}\right)= \begin{cases}0 & \text { if } u_{t} \leqslant 1-1 /(2 \mu) \\ 1 & \text { if } u_{t}>1-1 /(2 \mu)\end{cases}
$$

In words, a majority of rich high-ability agents will set $\tau_{t+1}^{\mathrm{O}}=0$, whereas a majority of poor (high-ability and low-ability) agents will set $\tau_{t+1}^{\mathrm{O}}=1$. Note that, in contrast with the Ramsey solution, $T^{\mathrm{O}}\left(u_{t}\right)$ is independent of $\hat{a}$.

Next, we rewrite equilibrium condition 2 by substituting in the optimal investment $e^{*}\left(\tau_{t}^{\mathrm{Y}}, \tau_{t+1}^{\mathrm{O}}\right)$. This yields the following functional equation:

$$
U\left(\tau_{t}^{\mathrm{Y}}\right)=\left(1-\beta+\tau_{t}^{\mathrm{Y}}+\beta T^{\mathrm{O}}\left(U\left(\tau_{t}^{\mathrm{Y}}\right)\right)\right) / 2,
$$

where $T^{\mathrm{O}}(.) \in\{0,1\}$ is given by (12). This functional equation is key for characterizing equilibria. Due to the discontinuity of the function $T^{\mathrm{O}}$ (.) (at $u_{t}=1-1 /(2 \mu)$ ), the functional equation has multiple solutions: in fact, it admits a continuum of solutions.

We now characterize the set of solutions to (13) and then show how the indeterminacy of the private investment rule leads to indeterminacy of equilibrium.

First, since $T^{\mathrm{O}}(.) \in\{0,1\}$, any solution of (13) must be a combination of the two linear functions $1-e^{*}\left(\tau_{t}^{\mathrm{Y}}, 0\right)=\left(1-\beta+\tau_{t}^{\mathrm{Y}}\right) / 2$ and $1-e^{*}\left(\tau_{t}^{\mathrm{Y}}, 1\right)=\left(1+\tau_{t}^{\mathrm{Y}}\right) / 2$. Second, rational expectations restrict the set of such combinations that can be allowed. In particular, any solution to the functional equation must be such that

$$
U\left(\tau_{t}^{\mathrm{Y}}\right) \in \begin{cases}\left\{\left(1-\beta+\tau_{t}^{\mathrm{Y}}\right) / 2,\left(1+\tau_{t}^{\mathrm{Y}}\right) / 2\right\} & \text { if } \tau_{t}^{\mathrm{Y}} \leqslant \beta-(1-\mu) / \mu \\ \left(1+\tau_{t}^{\mathrm{Y}}\right) / 2 & \text { if } \tau_{t}^{\mathrm{Y}}>\beta-(1-\mu) / \mu .\end{cases}
$$


Namely, if the decisive voter chooses a sufficiently large $\tau_{t}^{\mathrm{Y}}$, then the majority in the next period will be poor and will set $\tau_{t+1}^{\mathrm{O}}=1$. Hence, $U\left(\tau_{t}^{\mathrm{Y}}\right)=\left(1+\tau_{t}^{\mathrm{Y}}\right) / 2 .{ }^{8}$ However, if $\tau_{t}^{\mathrm{Y}} \leqslant \beta-(1-\mu) / \mu$, there are multiple self-sulfilling expectations. If agents expect not to be taxed when old, they choose high investment, and this leads to a majority of rich old who indeed will set $\tau_{t+1}^{\mathrm{O}}=0$. If, instead, they expect high future taxes, they choose low investments, and a majority of poor old who set $\tau_{t+1}^{\mathrm{O}}=1$ will then materialize. Consequently, multiple solutions exist in such range. ${ }^{9}$

Fig. 2 shows four possible such solutions. The solid lines represent $U\left(\tau_{t}^{\mathrm{Y}}\right)$. In panel $a$, for all tax rates on the young, agents expect a future majority of poor. Thus, $U\left(\tau_{t}^{\mathrm{Y}}\right)=\left(1+\tau_{t}^{\mathrm{Y}}\right) / 2$, for all $\tau_{t}^{\mathrm{Y}} \in[0,1]$. This expectation is always self-fulfilling, since $\left(1+\tau_{t}^{\mathrm{Y}}\right) / 2>1-1 /(2 \mu)$ and hence, by Eq. (12), $T^{\mathrm{O}}\left(\left(1+\tau_{t}^{\mathrm{Y}}\right) / 2\right)=1$. In contrast, in panels $\mathrm{b}, \mathrm{c}$ and $\mathrm{d}$, agents expect a majority of rich in the next period for some values of $\tau_{t}^{\mathrm{Y}}$, and for those values the solution must have $U\left(\tau_{t}^{\mathrm{Y}}\right)=\left(1-\beta+\tau_{t}^{\mathrm{Y}}\right) / 2$. In each of the three panels, $\theta$ denotes the largest tax rate that yields a majority of old rich in the next period (clearly, there is no $\theta$ in panel a). Panel b represents a case where agents expect a majority of rich old only for a compact range of very low values of $\tau_{t}^{\mathrm{Y}}$. In panels $\mathrm{c}$ and $\mathrm{d}$, a majority of rich emerges for a larger range of $\tau_{t}^{\mathrm{Y}}$. In panels $\mathrm{b}$ and $\mathrm{c}$, the function $U\left(\tau_{t}^{\mathrm{Y}}\right)$ is monotonic, while in panel $\mathrm{d}, U\left(\tau_{t}^{\mathrm{Y}}\right)$ is non-monotonic and features multiple jumps between the two linear functions. Note that panels $\mathrm{c}$ and $\mathrm{d}$ have been constructed so as to have the same $\theta$.

Having characterized the indeterminacy of $U\left(\tau_{t}^{\mathrm{Y}}\right)$, we move to the third equilibrium condition in Definition 2, and consider the political determination of $\tau_{t}^{\mathrm{Y}}$. To this end, it is useful to introduce the distinction between sincere and strategic voting. We say that agents vote strategically if they choose $\tau_{t}^{\mathrm{Y}}$ to induce a majority of rich at $t+1$ (recall that the old voters at $t$ gain, ceteris paribus, from a majority of rich at $t+1$, since these set $\tau_{t+1}^{\mathrm{O}}=0$, and $Z$ is decreasing in $\tau_{t+1}^{\mathrm{O}}$ ). We say that agents vote sincerely when their choice is not shaped by the desire to manipulate future political outcomes.

Suppose agents vote sincerely. Then, they set

$$
T^{\mathrm{Y}}=\arg \max _{\tau_{t}^{\mathrm{Y}} \in[0,1]} \hat{a} Z\left(\tau_{t}^{\mathrm{Y}}, 1\right)=\frac{1}{2},
$$

and the equilibrium features $\tau_{t}^{\mathrm{Y}}=\frac{1}{2}$ and $\tau_{t}^{\mathrm{O}}=1$. Intuitively, the young are taxed on the top of the Laffer curve, conditional on their expecting $100 \%$ taxation when old. Whether sincere voting is optimal depends on $U\left(\tau_{t}^{\mathrm{Y}}\right)$. In the case described in Fig. 2(a), sincere voting is the only option: a future majority of poor will emerge, irrespective of the current choice of $\tau_{t}^{\mathrm{Y}}$. But setting $\tau_{t}^{\mathrm{Y}}=\frac{1}{2}$ may be optimal even when $U\left(\tau_{t}^{\mathrm{Y}}\right)$ would allow the decisive voter to induce a majority of rich by setting a different choice of $\tau_{t}^{\mathrm{Y}}$. In particular, sincere voting is optimal if a future majority of rich can only be induced by setting $\tau_{t}^{\mathrm{Y}}$ very low (i.e., $\theta$ is small as in panel b of Fig. 2(b)). In general,

\footnotetext{
${ }^{8}$ To see why, note that, when $\tau_{t}^{\mathrm{Y}}>\beta-(1-\mu) / \mu$, even if agents expect $\tau_{t+1}^{\mathrm{O}}=0$, there will still be a majority of poor (since $\tau_{t}^{\mathrm{Y}}>\beta-(1-\mu) / \mu$ implies that $\left(1-\beta+\tau_{t}^{\mathrm{Y}}\right) / 2>1-1 /(2 \mu)$ ). Since this majority will set $100 \%$ redistribution, it would be irrational to expect $\tau_{t+1}^{\mathrm{O}}=0$.

${ }^{9}$ Since the solution features indeterminacy, stochastic sunspot equilibria may also exist. Here, we ignore such equilibria and focus on deterministic policy functions. The analysis of equilibria involving uncertainty is left to future research. We also ignore complications arising when the set of $\tau_{t}^{\mathrm{Y}}$ leading to a majority of rich is open. The analysis can be extended to cover such cases, but it requires some richer notation; see the working paper version for details [10].
} 

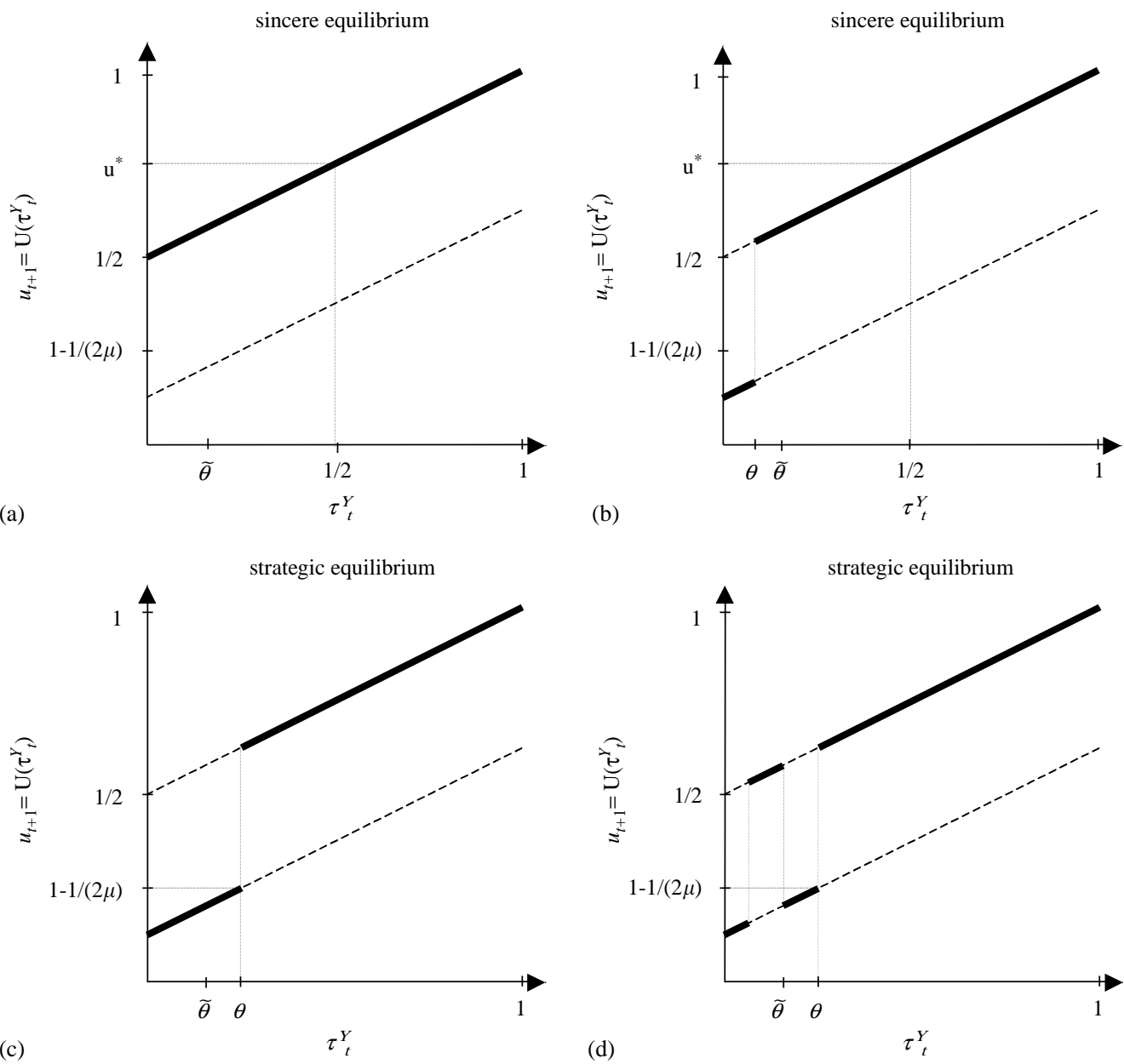

Fig. 2. The figures represent the equilibrium decision rule $u_{t+1}=U\left(\tau_{t}^{\mathrm{Y}}\right)$ under majority voting. (a) and (b) correspond to a sincere equilibrium (of Proposition 4) and (c) and (d) correspond to a strategic equilibrium. The parameter values behind the figures are $\mu=\frac{2}{3}$ and $\beta=\frac{3}{4}$, and in (c) and (d) $\theta$ is set to $\theta=\beta-(1-\mu) / \mu=\frac{1}{4}$.

a sincere equilibrium is sustained if, given $U\left(\tau_{t}^{\mathrm{Y}}\right), Z\left(\frac{1}{2}, 1\right)>Z\left(\tau_{t}^{\mathrm{Y}}, 0\right)$ for all $\tau_{t}^{\mathrm{Y}}$ inducing a future majority of rich.

The next proposition characterizes the set of sincere equilibria.

Proposition 2. Suppose $a \leqslant 1 / \mu$. Then for all parameters, there exists a set of sincere (stationary Markov) equilibria such that $\forall t, T^{\mathrm{O}}\left(u_{t}\right)$ is given as in $(12), T^{\mathrm{Y}}=\frac{1}{2}$, and

$$
U\left(\tau_{t}^{\mathrm{Y}}\right) \in \begin{cases}\left\{\left(1-\beta+\tau_{t}^{\mathrm{Y}}\right) / 2,\left(1+\tau_{t}^{\mathrm{Y}}\right) / 2\right\} & \text { if } \tau_{t}^{\mathrm{Y}} \leqslant \tilde{\theta}(\beta), \\ \left(1+\tau_{t}^{\mathrm{Y}}\right) / 2 & \text { if } \tau_{t}^{\mathrm{Y}}>\tilde{\theta}(\beta),\end{cases}
$$


where $\tilde{\theta}(\beta) \equiv(1+\beta-\sqrt{\beta(2+\beta)}) / 2$. The equilibrium outcome is unique and such that for $t \geqslant 1,10$

$$
\begin{aligned}
& \tau_{t}^{\mathrm{Y}}=1 / 2, \quad \tau_{t}^{\mathrm{O}}=1, \\
& u_{t}=3 / 4, \quad g_{t}+2 s_{t}=3 \mu / 8 .
\end{aligned}
$$

Note that although private investment behavior is indeterminate for a low range of $\tau_{t}^{\mathrm{Y}}$ (thus, formally, there is a continuum of sincere equilibria), this has no effect on equilibrium outcomes. The reason is that agents never find it optimal to choose $\tau_{t}^{\mathrm{Y}} \leqslant \tilde{\theta}(\beta)$, so that sincere equilibria differ from each other only in terms of out-of-equilibrium beliefs. All out-of-equilibrium beliefs consistent with a sincere equilibrium feature $\theta<\tilde{\theta}(\beta)$, where $\theta$ is the largest value of $\tau_{t}^{\mathrm{Y}}$ that can induce a majority of rich in the next period. ${ }^{11}$ With a slight abuse of terminology, we refer to a unique sincere equilibrium in the rest of the paper.

A sincere equilibrium is represented by the left-hand panel of Fig. 3 and Fig. 2(a) and (b). Fig. 3 shows the tax rate on the old $\left(T^{\mathrm{O}}(u)\right.$, solid line) and the young $\left(T^{\mathrm{Y}}\right.$, dashed line) as functions of $u$. In accordance with Eq. (12), $T^{\mathrm{O}}(u)$ prescribes zero taxation if there is a majority of old rich (i.e., $u \leqslant 1-1 /(2 \mu)$ ), and $100 \%$ taxation otherwise. Furthermore, $T^{\mathrm{Y}}=\frac{1}{2}$.

Consider next, strategic equilibria. We first establish that, among the tax rates on the young inducing a future majority of rich, the decisive voter always prefers the highest one. This is formally stated in the following lemma.

Lemma 2. If $T^{\mathrm{O}}(U(\theta))=0$, then $\forall t$, the decisive voter strictly prefers $\tau_{t}^{\mathrm{Y}}=\theta$ to any $\tau_{t}^{\mathrm{Y}}<\theta$.

An immediate implication of the lemma is that cases such as those described by panels $\mathrm{c}$ and $\mathrm{d}$ of Fig. 2 (recall that the two cases were constructed to have the same $\theta$ ) yield the same equilibrium outcome. More generally, for any equilibrium involving a non-monotonic function $U$ (such as panel d), there exists an equilibrium with a monotonic function (such as panel c) observationally equivalent to it, i.e., which gives rise to the same equilibrium functions $T^{\mathrm{Y}}, T^{\mathrm{O}}$ and the same equilibrium outcomes. In the rest of the paper we restrict, without loss of generality, attention to equilibria featuring monotonic policy functions $U\left(\tau_{t}^{\mathrm{Y}}\right)$, as in panels a-c of Fig. 2.

The next proposition characterizes the set of strategic equilibria.

Proposition 3. Suppose $a \leqslant 1 / \mu$. Then, if $\beta \geqslant(2-\mu)^{2} /(4 \mu)$, there exists a set of strategic (stationary Markov) equilibria such that $\forall t, T^{\mathrm{O}}\left(u_{t}\right)$ is given as in $(12), T^{\mathrm{Y}}=\theta \in[\tilde{\theta}(\beta), \beta-$ $(1-\mu) / \mu]$, and

$$
U\left(\tau_{t}^{\mathrm{Y}}\right)=U\left(\tau_{t}^{\mathrm{Y}} ; \theta\right) \equiv \begin{cases}\left(1-\beta+\tau_{t}^{\mathrm{Y}}\right) / 2 & \text { if } \tau_{t}^{\mathrm{Y}} \leqslant \theta \\ \left(1+\tau_{t}^{\mathrm{Y}}\right) / 2 & \text { if } \tau_{t}^{\mathrm{Y}}>\theta .\end{cases}
$$

\footnotetext{
10 The outcome in period $t=0$ is identical to that described in the proposition, except that the taxation of the old and the public good provision depend on the initial condition $u_{0}$.

$11 \tilde{\theta}(\beta)$ is the largest value $\theta$ consistent with a sincere equilibrium. It is calculated by solving $Z\left(\frac{1}{2}, 1\right)=Z(\tilde{\theta}, 0)$. Suppose that $\theta>\tilde{\theta}(\beta)$. Since the function $Z\left(\tau_{t}^{\mathrm{Y}}, 0\right)$ is continuous and strictly increasing in $\tau_{t}^{\mathrm{Y}}$ at $\tau_{t}^{\mathrm{Y}}=\tilde{\theta}(\beta)$, the voters would prefer choosing some $\tau_{t}^{\mathrm{Y}} \in[\tilde{\theta}(\beta), \theta]$ (and obtaining a majority of rich in period $t+1$ ) to setting $\tau_{t}^{\mathrm{Y}}=\frac{1}{2}$ (and getting a majority of poor in period $t+1)$. It follows that the sincere equilibrium breaks down when $\theta>\tilde{\theta}(\beta)$. This point is explained below.
} 

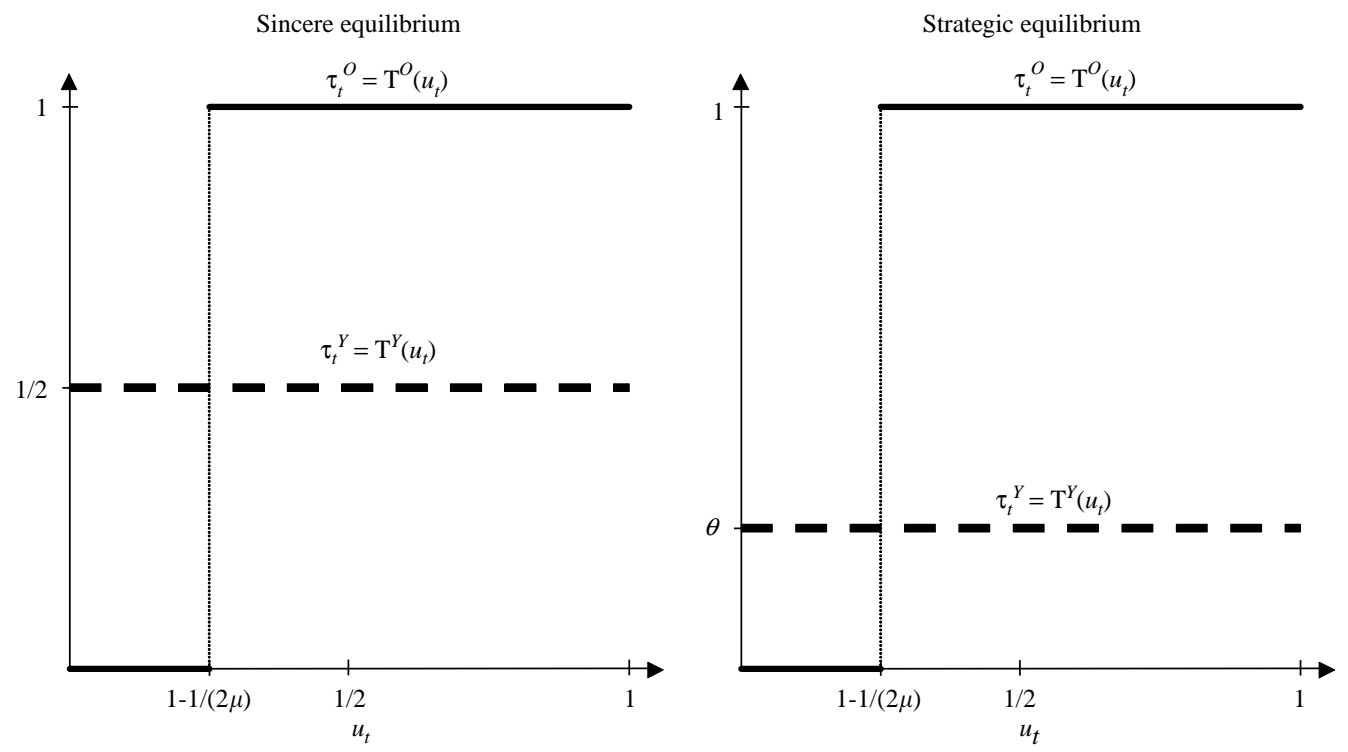

Fig. 3. The figures represent the equilibrium tax functions, $T^{\mathrm{Y}}$ and $T^{\mathrm{O}}\left(u_{t}\right)$, under majority voting. The left-hand (right-hand) panel corresponds to a sincere (strategic) equilibrium of proposition 4 . The parameter values behind the figures are $\mu=\frac{2}{3}$ and $\beta=\frac{3}{4}$, and in the right-hand panel, $\theta$ is set to $\theta=\beta-(1-\mu) / \mu=\frac{1}{4}$.

where $\tilde{\theta}(\beta)$ is defined in Proposition 2. The equilibrium outcome is indeterminate. In particular, for every $\theta \in[\tilde{\theta}(\beta), \beta-(1-\mu) / \mu]$, there exists one equilibrium outcome such that for $t \geqslant 1$,

$$
\begin{aligned}
& \tau_{t}^{\mathrm{Y}}=\theta, \quad \tau_{t}^{\mathrm{O}}=0, \\
& u_{t}=1 / 2-(\beta-\theta) / 2, \quad g_{t}+2 s_{t}=\mu(1+\beta-\theta) \theta / 2 .
\end{aligned}
$$

The condition $\beta \geqslant(2-\mu)^{2} /(4 \mu)$ guarantees that the range $[\tilde{\theta}(\beta), \beta-(1-\mu) / \mu]$ is not empty. Thus, an immediate corollary of Proposition 3 is that for a range of low $\beta$ 's where this condition is not satisfied, the sincere equilibrium is the unique equilibrium.

A strategic equilibrium is represented by Fig. 2(c) and the right-hand panel of Fig. 3. $T^{\mathrm{O}}\left(u_{t}\right)$ is the same as in the sincere equilibrium. However, in the strategic equilibrium, $T^{\mathrm{Y}}=\theta<\frac{1}{2}$.

Fig. 4 contrasts the tax revenue extracted from the young in the two equilibria described above. The left-hand panel corresponds to the sincere equilibrium of Fig. 2(b), while the right-hand panel corresponds to the strategic equilibrium of Fig. 2(c). The discontinuities in the humpshaped functions in Fig. 4 correspond to changes in expectations about the future majority: at $\tau_{t}^{\mathrm{Y}}=\theta$ the majority shifts from being rich to poor. In both cases, it is feasible to induce a majority of old rich in the next period, by setting $\tau_{t}^{\mathrm{Y}} \leqslant \theta$. In the sincere equilibrium, the optimal choice is $\tau_{t}^{\mathrm{Y}}=\frac{1}{2}$ since $\theta<\tilde{\theta}(\beta)$. In the strategic equilibrium it is optimal to set $\tau_{t}^{\mathrm{Y}}=\theta$ and induce a majority of rich in the next period since $\theta>\tilde{\theta}(\beta)$.

The next proposition summarizes the results established so far (proof in the text).

Proposition 4. When the government has access to public goods and general transfers, the political equilibrium has the following characterization. First, if $a<\frac{1}{2}$, the tax revenue is spent 

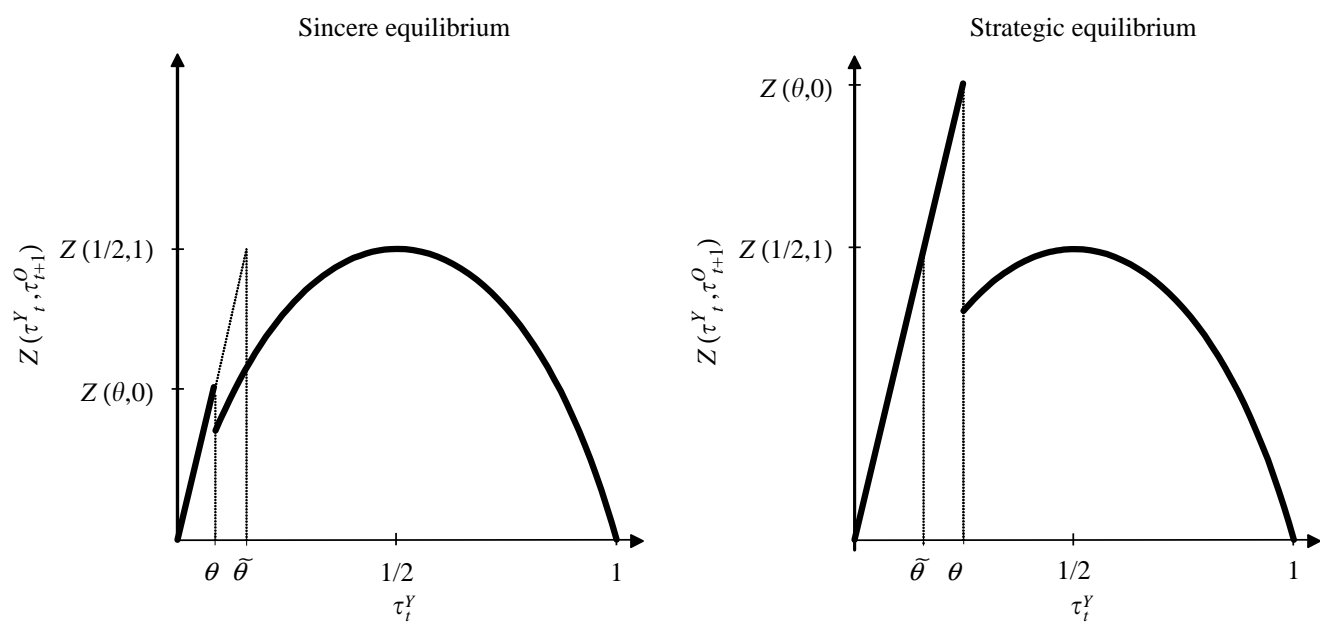

Fig. 4. The figures represent the tax revenues stemming from taxing the young, $Z$, under majority voting. The left-hand (right-hand) panel corresponds to a sincere (strategic) equilibrium of Proposition 4. The parameter values behind the figures are $\mu=\frac{2}{3}$ and $\beta=\frac{3}{4}$, and in the right-hand panel, $\theta$ is set to $\theta=\beta-(1-\mu) / \mu=\frac{1}{4}$.

entirely on general transfers $\left(g_{t}=0 \forall t\right)$, whereas if $a \geqslant \frac{1}{2}$, it is spent entirely on public good provision $\left(s_{t}=0 \forall t\right)$. Furthermore:

1. If $a \leqslant 1 / \mu$, then

(a) If $\beta<(2-\mu)^{2} /(4 \mu)$, there exists a unique sincere equilibrium as in Proposition 2.

(b) If $\beta \geqslant(2-\mu)^{2} /(4 \mu)$, the equilibrium is indeterminate. There exists both a sincere equilibrium as in Proposition 2, and a set of strategic equilibria as in Proposition 3.

2. If $a>1 / \mu$, there exists a unique equilibrium such that: $\forall t, T^{\mathrm{O}}\left(u_{t}\right)=1, T^{\mathrm{Y}}=\frac{1}{2}$, and $U\left(\tau_{t}^{\mathrm{Y}}\right)=\left(1+\tau_{t}^{\mathrm{Y}}\right) / 2$.

In summary, this section has established that the equilibrium is indeterminate as long as $\beta$ is sufficiently large. Indeterminacy stems from the discontinuity of the tax function $T^{\mathrm{O}}$ and, hence, from the indeterminate set of expectation-driven solutions to the functional Eq. (13) determining private investments.

\subsection{Positive and normative aspects of political equilibria}

The equilibrium level of government spending, $g_{t}+2 s_{t}$, differs across political equilibria. The lowest spending level is $\mu / 8$, which is attained by the strategic equilibrium with the lowest $\theta$. Government spending in the sincere equilibrium, $3 \mu / 8$, exceeds this minimum level. However, the sincere equilibrium need not deliver more spending than strategic equilibria since the maximum of the Laffer curve with respect to $\tau_{t}^{\mathrm{Y}}$ moves to the right when agents expect zero future taxation of the old. In general, the equilibrium level of spending may be higher or lower than in the Ramsey allocation. In particular, spending is increasing in $a$ in the Ramsey allocation, whereas it does not depend on $a$ in the political equilibrium.

The sincere equilibrium bears some resemblance to the Ramsey allocations in the case of $\lambda>\beta$, where the main tax burden falls on the old (see Proposition 1). There are two differences, though. 
First, when $A$ (the planner's marginal utility of spending) is low, the Ramsey planner does not tax the old at the maximum rate. Second, in the Ramsey allocation with $\lambda>\beta$, the young are subject to a tax $\tau_{t}^{\mathrm{Y}} \leqslant(1-\lambda) / 2$, while they are taxed at a $50 \%$ rate in the sincere equilibrium.

It is also interesting to compare the sincere equilibrium with the Rawlsian planner allocation of Corollary 1, as the latter maximizes the steady-state utility of the poor, who are in majority in the sincere equilibrium. Recall that the Rawlsian planner maximizes steady-state government expenditures by setting $\tau_{t}^{\mathrm{O}}=1$ and $\tau_{t}^{\mathrm{Y}}=0 \forall t$. In comparison, the sincere equilibrium imposes larger tax rates and delivers less spending. The reason for this excess taxation of the young is that voters have a short life horizon. Taxing the young is a liability on future generations that is not internalized by the current generation of voters. As a result, each generation inherits a narrower tax base than that required to maximize the provision of public good. Thus, in a dynamic sense, the sincere equilibrium is on the wrong side of the Laffer curve, due to the inability to commit to future policy outcomes. Still, a Pareto improvement is not possible: abstaining from taxing the young reduces the welfare of the initial old generation.

Strategic equilibria resemble Ramsey allocations with a low $\lambda$, where the entire tax burden falls on the young. However, the Ramsey allocation of Proposition 1 commands $\tau_{t}^{\mathrm{Y}}=(1+\beta) / 2$, whereas in a strategic equilibrium, $\tau_{t}^{\mathrm{Y}}=\theta<(1+\beta) / 2$. Therefore, for sufficiently large $a$, strategic equilibria feature inefficiently low government spending as compared to the allocation maximizing the average utility of voters. The reason is that old voters are subject to the political constraint that old rich agents remain in majority over time. However, if voters were to set $\tau_{t}^{\mathrm{Y}}=$ $(1+\beta) / 2$, as in their preferred Ramsey allocation, then $e^{*} \leqslant(1+\beta) / 4 \leqslant \frac{1}{2}$ and a majority of poor agents would arise in the next period. Thus, the political constraint that $\tau_{t}^{\mathrm{Y}} \leqslant \theta$ limits the extent to which the current generation of voters can extract a surplus from future generations.

We can also assess how different age and skill groups fare across the different equilibria. Provided that $\beta$ is sufficiently high, the old attain the maximum welfare in the strategic equilibrium with the highest $\theta$, i.e., $\theta=\beta-(1-\mu) / \mu$. Namely, if they could manipulate the expectations of the young, they would like them to believe that there is no redistribution in the future under a large set of current policies. As far as the young agents are concerned, the results are ambiguous and depend on parameters. ${ }^{12}$ An interesting general result holds if agents have low discount factors and the marginal utility of the public good is sufficiently high. In this case, all agents in the economy, except the old rich, prefer to be in a sincere equilibrium. Namely, all agents prefer, ex ante, to be in a sincere equilibrium. This result can be formally proved (proof omitted) by setting $\beta<\frac{1}{2}$, and letting $\mu a \rightarrow 1$.

\section{Targeted transfers}

In this section, we extend the analysis to transfer systems targeting specific sectors of the population. In particular, we focus on two sets of policies representing important shares of government expenditure in the real world: transfers targeted to the poor ("welfare transfers") and transfers targeted to old agents ("old age transfers"). Welfare transfers are denoted by $b \geqslant 0$, and are assumed

\footnotetext{
${ }^{12}$ In a stationary equilibrium, the expected utility of the high-ability young is $V^{y}=\left(e^{*}\left(\tau^{\mathrm{Y}}, \tau^{\mathrm{O}}\right)\right)^{2}+(1+\beta)(a g+s)$. Evaluating this expression in the sincere and strategic equilibria yields $V_{\text {Sinc }}^{y}=\frac{1}{16}+(3 \mu / 8)(1+\beta) \hat{a}$ and $V_{\text {Strat }}^{y}(\theta)=$ $(1+\beta-\theta)^{2} / 4+(\mu / 2)(1+\beta)(1+\beta-\theta) \theta \hat{a}$, respectively. There exist combinations of $\beta$ and $\theta$ such that $V_{\text {Sinc }}^{y}>$ $V_{\text {Strat }}^{y}(\theta)$, as well as combinations such that the converse is true. The ambiguity carries over to the welfare of the lowability young.
} 
to be paid to all agents earning a low (zero) income, irrespective of age. ${ }^{13}$ Old-age transfers are denoted by $p \geqslant 0$, and are assumed to be paid to all old agents irrespective of their income.

The set of utilities is modified as follows:

$$
\begin{aligned}
V_{t}^{o s}= & 1-\tau_{t}^{\mathrm{O}}+a g_{t}+s_{t}+p_{t}, \\
V_{t}^{o u}= & V_{t}^{o l}=a g_{t}+b_{t}+s_{t}+p_{t}, \\
V_{t}^{y}= & e_{t}\left(1-\tau_{t}^{\mathrm{Y}}+\beta\left(1-\tau_{t+1}^{\mathrm{O}}\right)\right)+\left(1-e_{t}\right)\left(b_{t}+\beta b_{t+1}\right) \\
& +a\left(g_{t}+\beta g_{t+1}\right)+s_{t}+\beta\left(s_{t+1}+p_{t+1}\right)-e_{t}^{2}, \\
V_{t}^{y l}= & a\left(g_{t}+\beta g_{t+1}\right)+s_{t}+\beta\left(s_{t+1}+p_{t+1}\right)+\left(b_{t}+\beta b_{t+1}\right) .
\end{aligned}
$$

The optimal investment becomes

$$
e^{*}\left(\hat{\tau}_{t}^{\mathrm{Y}}, \hat{\tau}_{t+1}^{\mathrm{O}}\right)=\left(1+\beta-\hat{\tau}_{t}^{\mathrm{Y}}-\beta \hat{\tau}_{t+1}^{\mathrm{O}}\right) / 2,
$$

where $\hat{\tau}_{t}^{i} \equiv b_{t}+\tau_{t}^{i}(i \in\{O, Y\})$ are the net tax rates in period $t$. It follows from Eq. (17) that welfare transfers have a direct distortionary effect on investments, while old age transfer have no such effect. Finally, the government budget constraint becomes

$$
\begin{aligned}
g_{t} & +2 s_{t}+p_{t}+\left(\mu\left(u_{t}+1-e^{*}\left(b_{t}+\tau_{t}^{\mathrm{Y}}, b_{t+1}+\tau_{t+1}^{\mathrm{O}}\right)\right)+2(1-\mu)\right) b_{t} \\
& =\mu\left(1-u_{t}\right) \tau_{t}^{\mathrm{O}}+\mu e^{*}\left(b_{t}+\tau_{t}^{\mathrm{Y}}, b_{t+1}+\tau_{t+1}^{\mathrm{O}}\right) \tau_{t}^{\mathrm{Y}},
\end{aligned}
$$

We impose the following incentive compatibility (IC) constraints:

$$
1-\tau_{t}^{\mathrm{Y}} \geqslant b_{t} \text { and } 1-\tau_{t}^{\mathrm{O}} \geqslant b_{t}
$$

to ensure that the rich (both old and young) are never worse off, after tax, than the poor. Otherwise, the successful agents would have an incentive to shirk, earn a low income and claim benefits. Note that we did impose a similar incentive compatibility constraint in the case of general transfer, namely $\tau^{i} \leqslant 1$, so (19) can be regarded as the natural generalization of the constraint that net taxation cannot exceed $100 \% .{ }^{14}$ Summarizing, feasibility is now defined as follows:

Definition 3. A feasible allocation is a sequence of transfers, public good provision, taxes and investments $\left\{b_{t}, s_{t}, p_{t}, g_{t}, \tau_{t}^{\mathrm{Y}}, \tau_{t}^{\mathrm{O}}, e_{t}\right\}_{t=0}^{\infty}$ that satisfies the implementability constraint, (17), the balanced budget constraint, (18), the IC constraints, (19), $b_{t} \geqslant 0, g_{t} \geqslant 0, s_{t} \geqslant 0$, and $p_{t} \geqslant 0 \forall t$.

\subsection{Public goods versus transfers targeted to the poor}

In this subsection, we consider welfare transfers. We start by the case where the government neither has access to general transfers nor to old age programs $\left(s_{t}=p_{t}=0 \forall t\right)$. The government can spend its revenue on either welfare programs specifically targeted to the poor or provision of public goods.

The equilibrium Definition 2 must be modified to include the endogenous choice of expenditure. It is useful to redefine the equilibrium policy functions in terms of the composite variables

\footnotetext{
${ }^{13}$ Note that we rule out the possibility that the government can target transfers to low-ability agents. This can be motivated by informational problems: the government may be unable to observe agents' ability.

14 The government could, in principle, keep track of the individual histories of income, and thereby not having to satisfy (19). However, this is an artifact of our simplifying assumption that individual income is perfectly correlated over time.
} 
$\hat{\tau}_{t}^{\mathrm{Y}}$ and $\hat{\tau}_{t}^{\mathrm{O}}$. Using (16) and the budget constraint (18) to eliminate $g_{t}$, and rearranging terms, the utility of the old voters can be expressed as follows:

$$
\begin{aligned}
& V_{t}^{o s}=1-\hat{\tau}_{t}^{\mathrm{O}}+a W\left(u_{t}, \hat{\tau}_{t}^{\mathrm{O}}\right)+a Z\left(\hat{\tau}_{t}^{\mathrm{Y}}, \hat{\tau}_{t+1}^{\mathrm{O}}\right)+(1-2 a) b_{t}, \\
& V_{t}^{o u}=V_{t}^{o l}=a W\left(u_{t}, \hat{\tau}_{t}^{\mathrm{O}}\right)+a Z\left(\hat{\tau}_{t}^{\mathrm{Y}}, \hat{\tau}_{t+1}^{\mathrm{O}}\right)+(1-2 a) b_{t},
\end{aligned}
$$

where $W$ and $Z$ are defined in (9) and (10), respectively.

Feasibility imposes a number of constraints. The IC constraints can be expressed in terms of the composite variables as follows:

$$
b_{t} \leqslant \hat{\tau}_{t}^{\mathrm{O}} \leqslant 1, \quad b_{t} \leqslant \hat{\tau}_{t}^{\mathrm{Y}} \leqslant 1 .
$$

Furthermore, $b_{t} \geqslant 0$ and $g_{t} \geqslant 0$. Using once more the budget constraint, (18), yields

$$
0 \leqslant b_{t} \leqslant \frac{1}{2} W\left(u_{t}, \hat{\tau}_{t}^{\mathrm{O}}\right)+\frac{1}{2} Z\left(\hat{\tau}_{t}^{\mathrm{Y}}, \hat{\tau}_{t+1}^{\mathrm{O}}\right) .
$$

We can now state the new formal equilibrium definition.

Definition 4. A (stationary Markov perfect) political equilibrium with public goods and targeted welfare transfers is defined as a set of functions $\left\langle T^{\mathrm{O}}, T^{\mathrm{Y}}, U, B\right\rangle$, where $T^{\mathrm{O}}:[0,1] \rightarrow[0,1]$, $T^{\mathrm{Y}} \in[0,1]$, and $B:[0,1] \rightarrow \mathbb{R}_{+}$are three public policy rules, $\hat{\tau}_{t}^{\mathrm{O}}=T^{\mathrm{O}}\left(u_{t}\right), \hat{\tau}_{t}^{\mathrm{Y}}=T^{\mathrm{Y}}$, and $b_{t}=B\left(u_{t}\right)$, and $U:[0,1] \rightarrow[0,1]$ is a private decision rule, $u_{t+1}=U\left(\hat{\tau}_{t}^{\mathrm{Y}}\right)$, such that given $u_{0}$, the following functional equations hold:

1. $\left\langle T^{\mathrm{O}}\left(u_{t}\right), T^{\mathrm{Y}}, B\left(u_{t}\right)\right\rangle=\arg \max _{\hat{\tau}_{t}^{\mathrm{Y}} \hat{\tau}_{t}^{\mathrm{O}}, b_{t}}\left\{W^{\mathrm{dec}}\left(u_{t}, \hat{\tau}_{t}^{\mathrm{O}}\right)+a Z\left(\hat{\tau}_{t}^{\mathrm{Y}}, \hat{\tau}_{t+1}^{\mathrm{O}}\right)+(1-2 a) b_{t}\right\}$ subject to the constraints (22)-(23), where

$$
W^{\operatorname{dec}}\left(u_{t}, \hat{\tau}_{t}^{\mathrm{O}}\right)= \begin{cases}1-\hat{\tau}_{t}^{\mathrm{O}}+a W\left(u_{t}, \hat{\tau}_{t}^{\mathrm{O}}\right) & \text { if } u_{t} \leqslant 1-1 /(2 \mu), \\ a W\left(u_{t}, \hat{\tau}_{t}^{\mathrm{O}}\right) & \text { if } u_{t}>1-1 /(2 \mu) .\end{cases}
$$

2. $U\left(\hat{\tau}_{t}^{\mathrm{Y}}\right)=1-e^{*}\left(\hat{\tau}_{t}^{\mathrm{Y}}, \hat{\tau}_{t+1}^{\mathrm{O}}\right)$, with $\hat{\tau}_{t+1}^{\mathrm{O}}=T^{\mathrm{O}}\left(U\left(\hat{\tau}_{t}^{\mathrm{Y}}\right)\right)$.

3. $T^{\mathrm{Y}}=\arg \max _{\tau_{t}^{\mathrm{Y} \in[0,1]}} a Z\left(\hat{\tau}_{t}^{\mathrm{Y}}, \hat{\tau}_{t+1}^{\mathrm{O}}\right)$ subject to $\hat{\tau}_{t+1}^{\mathrm{O}}=T^{\mathrm{O}}\left(U\left(\hat{\tau}_{t}^{\mathrm{Y}}\right)\right)$.

The main modification in Definition 4 is the additional policy rule, $b_{t}=B\left(u_{t}\right)$, determining the equilibrium choice of benefits as a function of the state variable $u_{t}$. It is straightforward to see that, whenever $a \geqslant \frac{1}{2}$, all old agents prefer public goods over targeted transfers. In this case, $B\left(u_{t}\right)=0$ for all $u_{t}$ and the equilibrium is identical to that of Proposition 4. In the rest of the section, we emphasize the case where $a<\frac{1}{2}$, implying that spending on public good provision provides lower utility on average than spending on welfare transfers. In this case, on the one hand, rich voters still prefer spending the entire budget on public good provision than on transfers from which they do not benefit (more formally, $B\left(u_{t}\right)=0$ if $u_{t} \leqslant 1-1 /(2 \mu)$ ). ${ }^{15}$ Poor voters, on the other hand, prefer to spend the budget on targeted transfers. Therefore, there is disagreement between the rich and the poor on how to spend the government revenue.

\footnotetext{
${ }^{15}$ Eq. (20) may give the wrong impression that the rich would also like targeted transfers when $a<\frac{1}{2}$. However, this argument disregards the constraint that $b_{t} \leqslant \hat{\tau}_{t}^{\mathrm{O}}$. When this constraint is taken into account, the formal analysis leads to the intuitive conclusion that the rich do not want to use public expenditure to help the poor.
} 
Consider first a sincere voting equilibrium, where the poor are in majority and would like to spend the whole budget on targeted transfers. The only interaction between the choice of $b$ and that of taxes is through the IC constraint (22). Therefore, it is possible to propose a candidate equilibrium where the budget is spent entirely on welfare transfers and the IC constraints are ignored and check, ex post, whether any of the IC constraints are violated in the resulting allocation. Abstracting from (22), the characterization of the policy functions $T^{\mathrm{O}}, T^{\mathrm{Y}}$ and $U$ is identical to that of Proposition 2, except that now they pin down the composite taxes $\hat{\tau}_{t}^{\mathrm{Y}}$ and $\hat{\tau}_{t}^{\mathrm{O}}$, rather than $\tau_{t}^{\mathrm{Y}}$ and $\tau_{t}^{\mathrm{O}}$. In particular, the candidate (sincere) equilibrium features constant composite rates $\hat{\tau}_{t}^{\mathrm{O}}=1$ and $\hat{\tau}_{t}^{\mathrm{Y}}=0.5$. By (17), this implies a stationary proportion of old high-ability poor $u_{t}=\frac{3}{4}$, once more as in Proposition 2. If the entire budget is spent on welfare transfers, then $b_{t}=3 \mu / 16$. In this case, $b<\hat{\tau}_{t}^{\mathrm{Y}}$ and $b<\hat{\tau}_{t}^{\mathrm{O}}$, implying that the IC constraints are satisfied in equilibrium. Thus, the sincere voting equilibrium is equivalent to that of Proposition 2. Moreover, given $a$, all agents earn the same utility even if voters can choose between general and targeted transfers.

Consider, next, strategic equilibria. Here, the rich are in majority and as long as $a>0$, they spend the entire budget on public good $\left(b_{t}=0\right)$. The policy functions $T^{\mathrm{O}}, T^{\mathrm{Y}}$ and $U$ are identical to the strategic equilibria of Proposition 4. Clearly, the implied allocation is feasible. Notably, while both taxes and population dynamics are as in Proposition 3, the equilibrium is less efficient. When the rich voters had access to general transfers, they choose these over public good provision whenever $a<\frac{1}{2}$. Now, instead, inefficient public good programs are preferred to welfare transfers when $a \in\left[0, \frac{1}{2}\right]$.

The following proposition summarizes the results so far (proof in the text).

Proposition 5. Assume that $a<\frac{1}{2}$. When the government has access to the two spendinginstruments public goods and transfers targeted to the poor, the political equilibrium is characterized as follows.

1. In any equilibrium, the policy function $T^{\mathrm{O}}$ is as in Eq. (12) and B is such that

$$
B\left(u_{t}\right)= \begin{cases}0 & \text { if } u_{t} \leqslant 1-1 /(2 \mu), \\ \frac{\mu}{2}\left(1-u_{t}\right) T^{\mathrm{O}}\left(U\left(T^{\mathrm{Y}}\right)\right) & \\ \quad+\frac{\mu}{2} T^{\mathrm{Y}} e^{*}\left(T^{\mathrm{Y}}, T^{\mathrm{O}}\left(U\left(T^{\mathrm{Y}}\right)\right)\right) & \text { if } u_{t}>1-1 /(2 \mu) .\end{cases}
$$

2. Sincere equilibria exist for all parameters, and are characterized by the same functions $T^{\mathrm{Y}}$, $T^{\mathrm{O}}$, and $U$ as in Proposition 2. The equilibrium outcome is unique and identical to that of Proposition 2, except that $g_{t}=s_{t}=0$ and $b_{t}=3 \mu / 16 \forall t \geqslant 1$.

3. Strategic equilibria exist under the same condition of Proposition 3 and are characterized by the same functions $T^{\mathrm{Y}}, T^{\mathrm{O}}$, and $U$ as in Proposition 3. The equilibrium outcome is indeterminate and, for every $\theta \in[\tilde{\theta}(\beta), \beta-(1-\mu) / \mu]$, there exists one equilibrium outcome identical to that of Proposition 3, except that $b_{t}=s_{t}=0$ and $g_{t}=\mu(1+\beta-\theta) \theta / 2 \forall t \geqslant 1$.

Proposition 5 states that the allocations resulting from equilibria where the poor hold power (sincere equilibria) are essentially identical, regardless of whether the government has access to general or welfare transfers. However, when $a<\frac{1}{2}$, equilibria where the rich hold power (strategic equilibria) provides all agents with lower utility when the government has access to targeted welfare programs than when it has access to general transfers. The reason is that the old rich prefer to spend the revenue on inefficient public goods ("white elephants"), rather than on more efficient targeted transfers, since they cannot benefit from such policies. Note that this result holds true for any $a>0$, so inefficiencies are potentially large. 
The extreme assumption that no general transfer program are available is not crucial. The qualitative result extends to the case when, like in many real world redistributive programs, transfers are a mixture of both general and targeted components, and agents can vote on the total provision of this bundle: the targeted component reduces the rate of return to rich voters of transfer programs, inducing them to prefer expensive and inefficient public good programs instead. In this generalization the threshold value of the marginal value of public goods would be lower, but there would still be a region where inefficient public goods are chosen.

The analysis so far raises the question of what the fundamental differences between general and targeted redistributive programs are. What allocations can be achieved with one instrument and not with the other? To address this question, we introduce the notion of equivalent allocations.

Definition 5. Consider two allocations $\Theta \equiv\left\{g_{t}, s_{t}, \tau_{t}^{\mathrm{Y}}, \tau_{t}^{\mathrm{O}}, e_{t}\right\}_{t=0}^{\infty}$ and $\Theta^{\prime} \equiv\left\{g_{t}^{\prime}, s_{t}^{\prime}, \tau_{t}^{\prime Y}, \tau_{t}^{\prime O}, e_{t}^{\prime}\right\}_{t=0}^{\infty}$ with the associated sequence of utilities, $\left\{V_{t}^{\omega}\right\}_{t=0}^{\infty}$ and $\left\{V_{t}^{\prime \omega}\right\}_{t=0}^{\infty}$ for $\omega \in\{o s, o u, o l, y, y l\}$. The allocations $\Theta$ and $\Theta^{\prime}$ are said to be equivalent if $e_{t}=e_{t}^{\prime}$ and $V_{t}^{\omega}=V_{t}^{\prime \omega}$ for all $t$.

In words, two allocations are "equivalent" if they give the same investments and give all agents the same utility in all periods. Note that this is stronger than all agents having the same discounted utility across allocation. The next lemma lays out the "sharpness" of the two types of transfer policies, general versus targeted transfers.

Lemma 3 (Part 1). For any feasible allocation $\Theta=\left\{b_{t}, g_{t}, s_{t}, p_{t}, \tau_{t}^{\mathrm{Y}}, \tau_{t}^{\mathrm{O}}, e_{t}\right\}_{t=0}^{\infty}$, there exists an equivalent feasible allocation $\Theta^{\prime}=\left\{b_{t}^{\prime}, g_{t}^{\prime}, s_{t}^{\prime}, p_{t}^{\prime}, \tau_{t}^{\prime Y}, \tau_{t}^{\prime O}, e_{t}^{\prime}\right\}_{t=0}^{\infty}$ such that for all $t \geqslant 0$,

$$
\begin{aligned}
b_{t}^{\prime} & =0, \quad g_{t}^{\prime}=g_{t}, \quad s_{t}^{\prime}=b_{t}+s_{t}, \quad p_{t}^{\prime}=p_{t}, \\
\tau_{t}^{\prime Y} & =b_{t}+\tau_{t}^{\mathrm{Y}}, \quad \tau_{t}^{\prime O}=b_{t}+\tau_{t}^{\mathrm{O}} .
\end{aligned}
$$

(Part 2). For some feasible allocations, there does not exists an equivalent feasible allocation such that $s_{t}=0$, for all $t \geqslant 0$.

Lemma 3 shows that, in combination with age-dependent income taxes, general transfers are a more powerful instrument than welfare programs. A combination of general transfers and agedependent income taxes allows a negative net taxation of old successful also if old-age transfers are zero and taxes are required to be non-negative. It follows that restrictions on the use of general transfers affect equilibria where the old successful hold the political power. Furthermore, it is clear that a Ramsey planner may strictly prefer to have access to general transfers but will always be indifferent to removing transfers targeted to the poor.

The results in Lemma 3 hinge on the constraint that income taxes be non-negative. If income taxes were allowed to be negative for some age group, the two types of transfers would become equivalent throughout. In particular, the following corollary holds.

Corollary 2. Assume the constraint $\tau_{t}^{\mathrm{Y}} \geqslant 0, \tau_{t}^{\mathrm{O}} \geqslant 0$, and $b_{t} \geqslant 0$ are replaced by the less strict constraints $\tau_{t}^{\mathrm{Y}}+b_{t} \geqslant 0, \tau_{t}^{\mathrm{O}}+b_{t} \geqslant 0$, and $b_{t} \geqslant 0$. Then general transfers and transfers targeted to the poor are equivalent instruments.

An interesting implication of the corollary is that if negative taxes were allowed in a system with welfare programs only, and the constraint that taxes are non-negative were replaced by the constraint that $\tau_{t}^{i}+b_{t} \geqslant 0$, for $i \in\{\mathrm{Y}, \mathrm{O}\}$, the old rich would choose the transfer system whenever $a<\frac{1}{2}$. In other words, "white elephants" would disappear. The old rich would offer subsidies 
to the poor in order to be able to set a negative tax rate on themselves and extract even more resources from the young. In Proposition 5, the inefficiency arises because, under a regime with welfare programs only, the rich old have a technology to tax the young, but not one to appropriate the tax revenue. Negative taxation introduces this missing technology.

\subsection{Public goods versus age-dependent transfers}

Age-dependent transfers have the opposite effect of transfers targeted to the poor: they extend the region of the parameter space where old agents (both rich and poor) choose transfers over public good provision. Clearly, from the point of view of the old voters, old-age transfers clearly dominate general transfers: the two instruments are identical from a distortionary standpoint, but the young are excluded from old age benefits. It is then easy to establish the following lemma.

Lemma 4. If $a \geqslant 1$, then, all old agents prefer public goods over old age programs. If $a<1$ then, all old agents prefer old age programs over public goods.

Therefore, the existence of old age programs causes an inefficient under-provision of public goods in the range $a \in\left(\frac{1}{2}, 1\right)$ compared with the choice of a utilitarian Ramsey planner (a planner with a pro-old bias would also use old age programs). The effect is symmetric on both sincere and strategic equilibria that are otherwise identical to Proposition 4. In reality, transfers targeted to the elderly often contain a mixture of inter-generational and intragenerational aspects [19]. Our analysis suggests that in this case-assuming that agents cannot alter the extent of the intragenerational redistribution in programs - the bias would be stronger in equilibria where the poor are politically decisive (sincere equilibria). In strategic equilibria, the two effects (bias in favor of transfers to the old against transfers to the poor) tend to offset each other.

\section{Age-dependent versus uniform taxation}

Throughout the paper, we have endowed the government with sharp instruments for intergenerational redistribution through its ability to condition taxes on age. In previous work [9], we studied economies in which the government has weaker instruments, and while it can transfer resources from rich to poor agents, it cannot condition taxes nor subsidies on age. Namely, the model of this paper nests [9] as a particular case if one sets $a=\frac{1}{2}, \mu=1$, and imposes that $\tau_{t}^{\mathrm{Y}}=\tau_{t}^{\mathrm{O}}=\tau_{t}$. Comparing the equilibrium outcomes of this paper with those of [9], yields interesting implications, both for welfare and for understanding the dynamics of these models.

In terms of welfare, we find that welfare need not be higher when the government has sharper instruments and can set age-dependent taxes than when taxes are age-independent as in [9]. Ruling out separate taxes on the old tends to lower taxes on the old. Since the current old would like to commit the choice of future voters to set lower tax in future, uniform taxation can serve as a stand-in for the lack of commitment. As argued by Krusell et al. [11] among others, enriching the set of policies by adding instruments that are less distortionary can, in a dynamic setting without commitment, lead to worse outcomes due to the temptation to increase the tax burden.

Our model provides an interesting and transparent example of this idea: consider a strategic equilibrium (with age-dependent taxation) of Proposition 3. Since the old can tax the young, the public-good provision is strictly positive-irrespective of the value of the public good. In contrast, with uniform taxation, the strategic equilibrium implies that the welfare state is terminated after one or two periods (see [9, Proposition 3]). Once the old rich become the majority, they will set 
taxes to zero, and this allocation will prevail. If the public good has a low marginal value (e.g. $a \leqslant \frac{1}{2}$ ), all future generations will be strictly better off with taxation being uniform. ${ }^{16}$ Moreover, from Proposition 1 it follows that with $a \leqslant \frac{1}{2}$ and a relatively high weight on future generations $(\lambda \geqslant \beta)$, the utilitarian planner will set taxes to zero every period. Thus, with uniform taxation, the politico-economic allocation converges to the Ramsey allocation (after at most two periods), while there is no convergence if the political system permits age-dependent taxation. In conclusion, restricting taxation to be uniform across age groups can serve as a commitment device for low taxation.

We end this paper by analyzing dynamics with and without age-dependent taxes. One of the equilibria in [9] features the perpetual survival of the transfer system, sharing some similarity with the sincere voting equilibrium of this paper. However, there are two important differences. First, in [9] if at time zero there is a political majority of old rich, positive transfer never arise in equilibrium, while in the present paper the initial distribution is irrelevant for the long-run outcome. Second, the equilibrium with redistribution in [9] converges to the steady-state asymptotically rather than after one period, and the state variable affects the optimal choice of redistribution even for a given identity of the political majority. The reason is that the uniform tax on the old and the young introduces a connection between taxation of the old and the investment of the young, implying that the state variable has persistent effects. In contrast, in this paper the state variable $u_{t}$ only influences the choice of taxation through the determination of the political majority, since with age-dependent taxes the government has access to an instrument that distorts ex ante but not ex post (when the tax rate on the old is determined, the tax-base is inelastic). This breaks the link between the current state variable and tax distortions: the chosen tax-rate for a given political majority is independent of the state variable, and all equilibria have a stationary character. ${ }^{17}$

\section{Acknowledgements}

We thank an associated editor for very useful comments.

\section{Appendix}

Proof of Proposition 1. The proof of the claim that $\tau_{0}^{\mathrm{O}}=1$ when $A>\beta /(\beta+\lambda)$ and zero otherwise is immediate. The second part descends from the solution of the following maximization

\footnotetext{
${ }^{16}$ To see this, consider a strategic equilibrium with $\theta=\beta$ and $\mu=1$. Existence of a strategic equilibrium with uniform taxation and zero taxation after one period requires that $\beta$ is sufficiently large, for example, $\beta \geqslant \frac{2}{3}$. After the initial period, the discounted utility of the young will, with age-dependent taxation, be $V_{\text {agedep }}^{\mathrm{Y}}=\left(1+\beta+\beta^{2}\right) / 4$, while with uniform taxation (equal zero both periods of life) it will be $V_{\text {uni }}^{\mathrm{Y}}=1$. However, in the initial period, only the old rich will gain on restricting policies to be uniform (presuming that the old poor are in majority). The initial young will lose (relative to a system with age-dependent taxation) because they will pay an initial tax of $\tau_{0}^{\mathrm{Y}}=\tau_{0}=\beta$ under either system, but will get lower transfers with uniform taxation (both when young and when old).

${ }^{17}$ Another case where there is a link between the state variable and tax distortions would be if the old high-ability poor, but only they, had a "second chance", i.e., if they were allowed to make a human capital investment in the second period. In this case, even the poor old may prefer a tax rate smaller than $100 \%$ in order to limit the distortion. Moreover, the human capital distribution among old agents would affect this choice, since it would determine the elasticity of the tax-base with respect to taxes on the old. Unfortunately, such version of the model cannot be solved analytically with the methods used in this paper, since the problem does not have a linear-quadratic structure.
} 
problem:

$$
\begin{aligned}
& \max _{\left\{\tau^{\mathrm{Y}} \in[0,1], \tau^{\mathrm{O}} \in[0,1]\right\}} L\left(\tau^{\mathrm{Y}}, \tau^{\mathrm{O}}\right) \\
& =\left\{\lambda \mu\left(e^{*}\left(\tau^{\mathrm{Y}}, \tau^{\mathrm{O}}\right)\left(1+\beta-\tau^{\mathrm{Y}}-\beta \tau^{\mathrm{O}}\right)-\left(e^{*}\left(\tau^{\mathrm{Y}}, \tau^{\mathrm{O}}\right)\right)^{2}\right)\right. \\
& \left.+(\beta+\lambda) A \mu\left(1+\beta-\tau^{\mathrm{Y}}-\beta \tau^{\mathrm{O}}\right)\left(\tau^{\mathrm{Y}}+\lambda \tau^{\mathrm{O}}\right) / 2\right\} .
\end{aligned}
$$

The solution must satisfy the following first-order conditions:

$$
\frac{\partial L}{\partial \tau^{\mathrm{Y}}}-\xi^{\mathrm{Y}}+\theta^{\mathrm{Y}}=0, \quad \text { and } \quad \frac{\partial L}{\partial \tau^{\mathrm{O}}}-\xi^{\mathrm{O}}+\theta^{\mathrm{O}}=0,
$$

where $\theta^{\mathrm{Y}}, \theta^{\mathrm{O}}$ are the Kuhn-Tucker multiplier associated with the constraints $\tau^{\mathrm{Y}} \geqslant 0$ and $\tau^{\mathrm{O}} \geqslant 0$, respectively, whereas $\xi^{\mathrm{Y}}$ and $\xi^{\mathrm{O}}$ are the Kuhn-Tucker multiplier associated with the constraints $\tau^{\mathrm{Y}} \leqslant 1$ and $\tau^{\mathrm{O}} \leqslant 1$, respectively.

Assume, first, that $\tau^{\mathrm{O}}=\xi^{\mathrm{Y}}=\xi^{\mathrm{O}}=\theta^{\mathrm{Y}}=0$. Then, one obtains

$$
\begin{aligned}
\tau^{\mathrm{Y}} & =(1+\beta) \frac{A-\lambda /(\beta+\lambda)}{2 A-\lambda /(\beta+\lambda)}, \\
\theta^{\mathrm{O}} & =\frac{1}{2} \mu A^{2} \frac{(1+\beta)(\beta-\lambda)(\beta+\lambda)^{2}}{2 A(\beta+\lambda)-\lambda},
\end{aligned}
$$

where $\tau^{\mathrm{Y}}<1$ and $\theta^{\mathrm{O}}>0$ as long as $\beta>\lambda$. This establishes part 1 .

Assume, next, that $\tau^{\mathrm{Y}}=\xi^{\mathrm{Y}}=\xi^{\mathrm{O}}=\theta^{\mathrm{O}}=0$. Then one obtains

$$
\begin{aligned}
\tau^{\mathrm{O}} & =\frac{(1+\beta)}{\beta} \frac{A-\beta /(\beta+\lambda)}{2 A-\beta /(\beta+\lambda)}, \\
\theta^{\mathrm{Y}} & =\frac{1}{2} \mu A^{2} \frac{(1+\beta)(\lambda-\beta)(\beta+\lambda)^{2}}{\beta(2 A(\beta+\lambda)-\beta)},
\end{aligned}
$$

where $\theta^{\mathrm{Y}}>0$ as long as $\beta<\lambda$. Furthermore, it is immediate to verify that $\tau^{\mathrm{O}}<1$ as long as $A<\beta /((1-\beta)(\beta+\lambda))$. If $A \geqslant \beta /((1-\beta)(\beta+\lambda))$, then $\tau^{\mathrm{O}}=1$ and $\xi^{\mathrm{O}}>0$. However, it remains to be checked whether $\tau^{\mathrm{Y}}=0$ continues to be a solution. Given $\tau^{\mathrm{O}}=1$, we obtain

$$
\frac{\partial L}{\partial \tau^{\mathrm{Y}}}-\xi^{\mathrm{Y}}+\theta^{\mathrm{Y}}=\frac{1}{2}\left(-\lambda \mu\left(1-\tau^{\mathrm{Y}}\right)+(\beta+\lambda) A \mu\left(1-\lambda-2 \tau^{\mathrm{Y}}\right)\right)+\theta^{\mathrm{Y}}=0 .
$$

The solution features $\tau^{\mathrm{Y}}=0$ and $\theta^{\mathrm{Y}}>0$ if and only if $A \leqslant \lambda /((1-\lambda)(\beta+\lambda))$. For larger values of $A$, the solution instead features $\theta^{\mathrm{Y}}=0$ and

$$
\tau^{\mathrm{Y}}=\frac{A(1-\lambda)-\lambda /(\beta+\lambda)}{2 A-\lambda /(\beta+\lambda)} .
$$

This establishes part 2.

Finally, consider the knife-edge case where $\beta=\lambda$. Then, the objective function can be written as

$$
\bar{L}(x)=\beta \mu\left((1+\beta-x) e^{*}(x)-\left(e^{*}(x)\right)^{2}\right)+\beta A \mu(1+\beta-x) x,
$$

where $x \equiv \tau^{\mathrm{Y}}+\beta \tau^{\mathrm{O}}$. The first-order conditions yields the result in part 3 . 
Proof of Proposition 2. First, suppose that at time $t$ agents know that $\tau_{t}^{\mathrm{Y}}=\frac{1}{2}$ and expect that $\tau_{t+1}^{\mathrm{O}}=1$. Then, $e^{*}\left(\frac{1}{2}, 1\right)=u_{t+1}=\frac{3}{4}>1-1 /(2 \mu)$ for all $\mu$ in [0,1]. By (12), this implies that $\tau_{t+1}^{\mathrm{O}}=1$, fulfilling initial expectations. Therefore, as long as, given $U\left(\tau_{t}^{\mathrm{Y}}\right)$ as in (15), the decisive voter finds it optimal to set $\tau_{t}^{\mathrm{Y}}=\frac{1}{2}$, a sincere equilibrium exists. To establish that setting $\tau_{t}^{\mathrm{Y}}=\frac{1}{2}$ is optimal for the decisive voter, we note two properties of the $Z$ (.) function. First, standard algebra shows that $Z\left(\tau_{t}^{\mathrm{Y}}, 0\right)=a \mu \tau^{\mathrm{Y}}\left(1+\beta-\tau_{t}^{\mathrm{Y}}\right) / 2$ is strictly increasing in the range $\tau_{t}^{\mathrm{Y}} \in[0, \tilde{\theta}(\beta)]$. Second, $Z\left(\tau_{t}^{\mathrm{Y}}, 0\right)>Z\left(\tau_{t}^{\mathrm{Y}}, 1\right)$. Therefore, given $U\left(\tau_{t}^{\mathrm{Y}}\right)$ as in $(15), Z(\tilde{\theta}(\beta), 0)$ is an upper bound to the tax revenue that the decisive voter can extract from the young by deviating from the proposed equilibrium and voting strategically for some $\tau_{t}^{\mathrm{Y}} \in[0, \tilde{\theta}(\beta))$. However, such deviation is never optimal since $Z(1 / 2,1)=Z(\tilde{\theta}(\beta), 0)=\frac{1}{8}$. Therefore, $\forall \tau_{t}^{\mathrm{Y}} \in[0, \tilde{\theta}(\beta))$, $Z(1 / 2,1)>Z\left(\tau_{t}^{\mathrm{Y}}, 0\right)$, and sincere voting is an equilibrium.

Proof of Lemma 2. Suppose, first, $U\left(\tau_{t}^{\mathrm{Y}}\right)$ to be monotonic. Then, $T^{\mathrm{O}}(U(\theta))=0 \Rightarrow \forall \tau_{t}^{\mathrm{Y}} \leqslant \theta$, $T^{\mathrm{O}}\left(U\left(\tau_{t}^{\mathrm{Y}}\right)\right)=0$ and $U\left(\tau_{t}^{\mathrm{Y}}\right)=\left(1+\beta-\tau_{t}^{\mathrm{Y}}\right) / 2$. Consequently, the relevant payoff function in the range $\tau_{t}^{\mathrm{Y}} \in[0, \theta]$ is $Z\left(\tau_{t}^{\mathrm{Y}}, 0\right)$. Next, note that $Z\left(\tau_{t}^{\mathrm{Y}}, 0\right)=a \mu \tau_{t}^{\mathrm{Y}}\left(1+\beta-\tau_{t}^{\mathrm{Y}}\right) / 2$ is a hump-shaped function of $\tau_{t}^{Y}$, with a maximum at $(1+\beta) / 2$. Since $\theta \leqslant \beta-(1-\mu) / \mu<$ $(1+\beta) / 2$ (since $\beta<1$ ), it follows that $Z\left(\tau_{t}^{\mathrm{Y}}, 0\right)$ must be increasing in $\tau_{t}^{\mathrm{Y}}$ in the range $\tau_{t}^{\mathrm{Y}} \in$ $[0, \theta]$, so that voters never choose $\tau_{t}^{Y}<\theta$. This establishes the lemma under the condition that $U\left(\tau_{t}^{\mathrm{Y}}\right)$ is monotonic. To generalize it, observe that, when $U\left(\tau_{t}^{\mathrm{Y}}\right)$ is non-monotonic, there exists a subset $S \subset[0, \theta)$ such that, for $\tau_{t}^{\mathrm{Y}} \in S, T^{\mathrm{O}}\left(U\left(\tau_{t}^{\mathrm{Y}}\right)\right)=1$. However, for any $\tau_{t}^{\mathrm{Y}} Z\left(\tau_{t}^{\mathrm{Y}}, 1\right)<$ $Z\left(\tau_{t}^{\mathrm{Y}}, 0\right)$. Therefore, setting $\tau_{t}^{\mathrm{Y}}=\theta$ is a fortiori preferred to any $\tau_{t}^{\mathrm{Y}}<\theta$ when $U\left(\tau_{t}^{\mathrm{Y}}\right)$ is nonmonotonic.

Proof of Proposition 3. The condition $\beta \geqslant(2-\mu)^{2} /(4 \mu)$ implies that $\tilde{\theta}(\beta) \leqslant \beta-(1-\mu)$ $/ \mu$. Let $U\left(\tau_{t}^{\mathrm{Y}}\right)=U\left(\tau_{t}^{\mathrm{Y}} ; \theta\right)$, with $\theta \in[\tilde{\theta}(\beta), \beta-(1-\mu) / \mu]$. Given Lemma 2 , in order to establish that the decisive voter chooses $\tau_{t}^{\mathrm{Y}}=\theta$, it is sufficient to establish that $Z(\theta, 0) \geqslant Z\left(\frac{1}{2}, 1\right)$, for all $\theta \in[\tilde{\theta}(\beta), \beta-(1-\mu) / \mu]$. We know from the proof of Proposition 2 that $Z(\tilde{\theta}(\beta), 0)=$ $Z\left(\frac{1}{2}, 1\right)=\frac{1}{8}$. Moreover, $Z(\theta, 0)$ is increasing in $\theta$ in the relevant range. Therefore, $Z(\theta, 0)$ $\geqslant Z\left(\frac{1}{2}, 1\right)$ and setting $\tau_{t}^{\mathrm{Y}}=\theta$ is indeed optimal. The rest of the proof follows from discussion in the text.

Proof of Lemma 3. Consider part 1. First, note that the composite tax rates are identical under the two allocations, that is, $\hat{\tau}_{t}^{i}=\hat{\tau}_{t}^{\prime i}, \forall t \geqslant 0$ and $i \in\{\mathrm{Y}, \mathrm{O}\}$. Thus, for all $t \geqslant 0$ we have $e_{t}^{*}=e_{t}^{* *}$. Second, an inspection of Eq. (1) immediately shows that all individuals have identical private and public consumption, both as old and as young, in the two allocations. Third, the budget constraint (18) is satisfied for both allocations since $g_{t}+2\left(s_{t}+b_{t}\right)+p_{t}=g_{t}^{\prime}+2 s_{t}^{\prime}+p_{t}$. Moreover, if the incentive compatibility constraint, (19), holds under the allocation $\Theta$, it obviously holds under $\Theta^{\prime}$. In addition, the same constraint implies that the tax rates associated with the latter allocation are bounded within the interval $\tau_{t}^{\prime Y} \in\left[b_{t}^{\prime}, 1\right]=[0,1]$ and $\tau_{t}^{\prime O} \in[0,1]$, since

$$
1 \geqslant b_{t}+\tau_{t}^{\mathrm{Y}}=\tau_{t}^{\prime Y}, \quad 1 \geqslant b_{t}+\tau_{t}^{\mathrm{O}}=\tau_{t}^{\prime O}
$$

and, since $b_{t} \geqslant 0, \tau_{t}^{\prime Y} \geqslant \tau_{t}^{\mathrm{Y}} \geqslant 0$ and $\tau_{t}^{\prime O} \geqslant \tau_{t}^{\mathrm{O}} \geqslant 0$. Finally, $s_{t}^{\prime O} \geqslant s_{t}^{\mathrm{O}} \geqslant 0$. 
Consider now part 2, which we will establish by an example. Suppose $\Theta$ has $g_{t}=0$ for all $t$. In order for an alternative allocation, $\Theta^{\prime}$, with $s_{t}^{\prime}=0$ for all $t \geqslant 0$, to be equivalent, it must then, provide the same private consumption to all agents, for all $t \geqslant 0$, i.e.,

$$
\begin{aligned}
1-\tau_{t}^{\prime O}+p_{t}^{\prime} & =1-\tau_{t}^{\mathrm{O}}+s_{t}+p_{t}, \\
b_{t}^{\prime}+p_{t}^{\prime} & =b_{t}+s_{t}+p_{t}, \\
1-\tau_{t}^{\prime Y} & =1-\tau_{t}^{\mathrm{Y}}+s_{t}, \\
b_{t}^{\prime} & =b_{t}+s_{t},
\end{aligned}
$$

representing, respectively, the consumption of old successful, old unsuccessful, young successful and young unsuccessful. The second and fourth equation, implies that $p_{t}^{\prime}=p_{t}$. Using this in the first equation, we get $\tau_{t}^{\prime O}=\tau_{t}^{\mathrm{O}}-s_{t}$. For feasible allocations with $s_{t}>\tau_{t}^{\mathrm{O}}$, the equivalent allocation with $s_{t}=0$ is not feasible since it violates the condition $\tau_{t}^{\prime} \geqslant 0$.

Proof of Corollary 2. For the feasible allocation $\Theta=\left\{b_{t}, g_{t}, s_{t}, p_{t}, \tau_{t}^{\mathrm{Y}}, \tau_{t}^{\mathrm{O}}, e_{t}\right\}_{t=0}^{\infty}$, construct allocation $\Theta^{\prime}=\left\{b_{t}^{\prime} g_{t}, s_{t}^{\prime}, p_{t}, \tau_{t}^{\prime Y}, \tau_{t}^{\prime O}, e_{t}^{\prime}\right\}_{t=0}^{\infty}$ such that $b_{t}^{\prime}=b_{t}+s_{t}, \tau_{t}^{\prime O}=\tau_{t}^{\mathrm{O}}-s_{t}, \tau_{t}^{\prime Y}=\tau_{t}^{\mathrm{Y}}-s_{t}$, maintaining the private consumption of all groups. Furthermore, because $\tau_{t}^{\prime Y}+b_{t}^{\prime}=\tau_{t}^{\mathrm{Y}}+b_{t}$ and $\tau_{t}^{\prime O}+b_{t}^{\prime}=\tau_{t}^{\mathrm{O}}+b_{t}$ investment choices are the same in the two allocations, the government budget constraint is satisfied, $\tau_{t}^{\prime Y}+b_{t}^{\prime} \geqslant 0, \tau_{t}^{\prime O}+b_{t}^{\prime} \geqslant 0$ and the incentive constraints are satisfied. All other negativity constraints are implied by the feasibility of $\Theta$.

\section{References}

[1] A. Alesina, G. Tabellini, A positive theory of fiscal deficits and government debt, Rev. Econ. Stud. 57 (1990) 403-414.

[2] M. Azzimonti Renzo, On the dynamic inefficiency of governments, University of Iowa, Mimeo, 2005.

[3] R. Benabou, Unequal societies: income distribution and the social contract, Amer. Econ. Rev. 90 (2000) 96-129.

[4] T. Besley, S. Coate, Sources of inefficiency in a representative democracy: a dynamic analysis, Amer. Econ. Rev. 88 (1998) 139-156.

[5] K. Chen, Z. Song, A Markovian social contract of social security, University of Southern California, Mimeo, 2005.

[6] L. Forni, Social security as Markov equilibrium in olg models, Rev. Econ. Dynam. 8 (2005) 178-194.

[7] M. Gonzalez Eiras, D. Niepelt, Sustaining social security, IIES Seminar Paper, vol. 731, 2004.

[8] J. Hassler, P. Krusell, K. Storesletten, F. Zilibotti, The dynamics of government, J. Monet. Econ. 52 (2005) 1331-1358.

[9] J. Hassler, J.V. Rodríguez Mora, K. Storesletten, F. Zilibotti, The survival of the welfare state, Amer. Econ. Rev. 93 (2003) 87-112.

[10] J. Hassler, K. Storesletten, F. Zilibotti, Democratic public good provision, CEPR Discussion Paper, No. $4296,2003$.

[11] P. Krusell, V. Quadrini, J.V. Ríos-Rull, Are consumption taxes really better than income taxes?, J. Monet. Econ. 37 (1996) 475-503.

[12] A. Lizzeri, N. Persico, The provision of public goods under alternative electoral incentives, Amer. Econ. Rev. 91 (2001) 225-245.

[13] G.M. Milesi-Ferretti, R. Perotti, M.V. Rostagno, Electoral systems and public spending, Quart. J. Econ. 117 (2002) 609-657.

[14] T. Persson, L.E.O. Svensson, Why a stubborn conservative would run a deficit: policy with time-inconsistent preferences, Quart. J. Econ. 104 (1989) 325-345.

[15] T. Piketty, Social mobility and redistributive politics, Quart. J. Econ. 110 (1995) 551-584.

[16] J.A. Robinson, R. Torvik, White elephants, J. Public Econ. 89 (2005) 197-210.

[17] Z. Song, Dynamic inequality and social security, Mimeo, Stockholm University, 2005.

[18] Z. Song, Ideology and the determination of public policies over time, Mimeo, Stockholm University, 2005.

[19] G. Tabellini, The politics of intergenerational redistribution, J. Polit. Economy 99 (1991) 335-357. 